\title{
Maximizing the identification of QTL for pre-harvest sprouting resistance using seed dormancy measures in a white-grained hexaploid wheat population
}

\author{
Sachin Kumar • Ron E. Knox $\cdot$ Fran R. Clarke $\cdot$ Curtis J. Pozniak • \\ Ron M. DePauw $\cdot$ Richard D. Cuthbert $\cdot$ Stephen Fox
}

Received: 21 November 2014/ Accepted: 30 April 2015/Published online: 20 May 2015

(C) The Author(s) 2015. This article is published with open access at Springerlink.com

\begin{abstract}
Pre-harvest sprouting in spring wheat causes significant financial loss to growers throughout the world and sprouting damage can be reduced by growing resistant genotypes. Several genetic factors, especially those related to seed dormancy, are involved in the control of pre-harvest sprouting resistance. The objective of this study was to identify quantitative trait loci (QTL) influencing pre-harvest sprouting resistance from multiple measures of dormancy at multiple germination intervals on seed harvested across multiple environments. A doubled haploid mapping population of 91 individuals derived from a cross of two Canadian white-seeded spring
\end{abstract}

Electronic supplementary material The online version of this article (doi:10.1007/s10681-015-1460-x) contains supplementary material, which is available to authorized users.

S. Kumar $(\bowtie) \cdot$ R. E. Knox $(\bowtie) \cdot$ F. R. Clarke .

R. M. DePauw · R. D. Cuthbert

Semiarid Prairie Agricultural Research Centre,

Agriculture and Agri-Food Canada, 1030, 1 Airport Road,

Swift Current, SK S9H 3X2, Canada

e-mail: sachinkpsingh@gmail.com

R. E. Knox

e-mail: ron.knox@agr.gc.ca

C. J. Pozniak

Crop Development Centre, University of Saskatchewan, Saskatoon, SK S7N 5A8, Canada

S. Fox

DL Seeds Inc., PO Box 98, St Norbert Postal Station,

Winnipeg, MB, Canada wheat genotypes, SC8021-V2 (pre-harvest sprouting resistant) and AC Karma (moderately susceptible to pre-harvest sprouting) was used for QTL mapping. Daily germination counts were analysed using germination index, germination resistance and percent germination at intervals of 3, 5, 7, 10, 14 and 21 days from spike samples collected from six field and one greenhouse environments in Saskatchewan, Canada. Continuous frequency distributions at certain measure-durations indicated genetic complexity of dormancy segregation in the SC8021-V2/AC Karma cross. Composite interval mapping detected significant $(p \leq 0.05)$ QTL associated with resistance to pre-harvest sprouting on all 21 wheat chromosomes. Of the 26 total QTL, six were novel and the rest were detected either at the same marker or overlapping a marker interval reported in other studies. QTL expressed consistently for germination index, germination resistance and percent germination at different germination durations on chromosomes 2B, 4A, 5D and 6D. QTL identified on homoeologous chromosomes $4 \mathrm{~A}, 4 \mathrm{~B}$ and $4 \mathrm{D}$ with chromosome specific molecular variants of SSR marker wmc617 suggest a conserved region for controlling dormancy on group four. The majority of QTL mapped in regions known to contain factors affecting different components of pre-harvest sprouting resistance like seed dormancy, seed coat colour, ABA responsiveness and alpha-amylase activity. This study demonstrated that using multiple measures of seed dormancy 
at multiple intervals of germination enhanced identification of QTL affecting dormancy in white-seeded hexaploid wheat.

Keywords Wheat - Dormancy · Pre-harvest sprouting · Germination index · Germination resistance $\cdot$ Percent germination $\cdot$ QTL

\section{Introduction}

Hexaploid wheat (Triticum aestivum L. em Thell.) is widely grown in a variety of climates the world over, and contributes up to $40 \%$ of the world's food (Braun et al. 2010). The grain contains many essential nutrients including fiber, carbohydrates, proteins, vitamins, minerals, and other bioactive compounds that are important in human nutrition (Gillies et al. 2012; Balyan et al. 2013). Pre-harvest sprouting is the precocious germination of grains in the spike due to early breakage of seed dormancy usually the result of moist weather conditions that persist after physiological maturity. In Canada, the cost of downgrading because of pre-harvest sprouting damage was estimated at about 100 million dollars annually (Clarke et al. 2005). Seed dormancy in wheat plays a critical role in protection against pre-harvest sprouting (Mares 1987). Both too low or too high seed dormancy can be undesirable by either allowing pre-harvest sprouting after seed maturity if too low or delaying germination after seed sowing if too high. Therefore, development of wheat genotypes with a balanced degree of seed dormancy is needed. Temperature and moisture during grain development affect the expression of dormancy and pre-harvest sprouting resistance. Under Canadian conditions, DePauw and McCaig (1991) compared various assays to measure sprouting resistance, seed dormancy and alpha-amylase activity, and their relative components of variation. They reported significant correlation among traits, and the genotypic effects accounted for $44-90 \%$ of the phenotypic variation. Heritability of the various traits varied from 0.59 to 0.93 . Identification and incorporation of genetic factors underlying resistant genotypes is a key to improve resistance to pre-harvest sprouting (McCaig and DePauw 1992; Flintham 2000; Mares et al. 2005; DePauw et al. 2012).

Pre-harvest sprouting is a complex trait, but phenotypic evaluation of experimental genotypes is generally straightforward and is based on the sprouting rate. Evaluation of threshed seeds, instead of intact spikes where the embryo is concealed by the lemma and palea, is used to characterize dormancy level. Germination index (GI), germination resistance (GR) and percent germination (PG) are common measurements for characterizing resistance to pre-harvest sprouting based on seed dormancy (Rasul et al. 2009; Singh et al. 2010; Knox et al. 2005, 2012).

The complexity of control of pre-harvest sprouting is demonstrated by the wide range of factors involved in the trait. The majority of genetic factors, including morphologic, physiologic, and biochemical are extensively reviewed elsewhere (DePauw and McCaig 1991; Fang and Chu 2008; Kulwal et al. 2010; Graeber et al. 2012; DePauw et al. 2012; Gao et al. 2013). One facet of this complex trait deals with the balance of plant growth regulators abscisic acid (ABA) and gibberellic acid (GA) in their control of alpha-amylase enzyme activity. The level of viviparous-1 ( $V p l)$ gene expression in mature embryos positively regulates ABA sensitivity and promotes seed dormancy. Huang and Brule-Babel (2012) transferred a Vpl homolog from maize (Zea mays L.) into an elite hexaploid wheat genotype, Zheng9023, through Agrobacteriummediated transformation. After transformation, Zheng9023 had enhanced seed dormancy with significant reduction in alpha-amylase activity. Another factor reported by Nakamura et al. (2011) involved a candidate gene homolog of MOTHER OF FT AND TFL1 (MFT) that acts in seed dormancy regulation during physiological maturity. In Arabidopsis, MFT was discovered as homolog of FLOWERING LOCUS $T(F T)$, a floral promoter and TERMINAL FLOWER 1 (TFL1), floral inhibitor (Hedman et al. 2009). Interestingly, in wheat, these MFT homologs (TaMFT) colocalized with the seed dormancy QTL QPhs.ocs-3A.1 on chromosome 3A (Mori et al. 2005). In a subsequent study, Liu et al. (2013) cloned the gene TaPHS1 underlying the QTL Qphs.pseru-3AS on the short arm of chromosome $3 \mathrm{~A}$ in white-seeded wheat using comparative and map-based cloning approaches. They discovered two single nucleotide polymorphisms (SNPs) in the promoter region and three SNPs in the TaPHS1 gene that altered pre-harvest sprouting resistance.

Another facet of pre-harvest sprouting in wheat relates to seed coat colour in which red coats are generally more resistant than seeds with white coats 
(Nilsson-Ehle 1914; DePauw and McCaig 1983; Himi et al. 2002). It is thought that the relationship between pre-harvest sprouting resistance and grain colour is due to pleiotropic characteristics of three red alleles (Flintham 2000; Himi and Noda 2005). The presence of any one or more of the three red alleles $(R-A l b, R$ $B 1 b$ and $R-D 1 b)$ confers red grain colour, whereas non-red alleles are present in the homozygous condition at all loci in grains with white colour (McIntosh et al. 1998). DePauw and McCaig (1983) presented evidence for a mechanism for dormancy independent of seed coat color. However, understanding the biochemical mechanism behind red and non-red grain colour with respect to pre-harvest sprouting response remains a challenge.

The genetic control of pre-harvest sprouting resistance is complex, factors responsible for resistance are dispersed on almost every wheat chromosome and complex interactions occur between QTL $(\mathrm{Q} \times \mathrm{Q})$ and/or among environments $(\mathrm{Q} \times \mathrm{Q} \times \mathrm{E})$ (Kulwal et al. 2004; Imtiaz et al. 2008; Kumar et al. 2009; Mohan et al. 2009). Also, the effects of QTL range from minor to major corresponding to a range in phenotypic expression from susceptible to resistant. As with DePauw and McCaig (1991) in the study of heritability, in order to deal with the complexity of pre-harvest sprouting resistance and identify associated QTL, different tests such as wetting spikes in an artificial rain simulator, threshed seed germination counts for dormancy, and alpha-amylase activity measured by falling number have been conducted (Roy et al. 1999; Mares et al. 2005; Imtiaz et al. 2008; Rasul et al. 2009). Knox et al. (2012) reported GI, GR and PG measures each at 7,14 and 21 days intervals from the start of germination across multiple environments. The authors emphasized that measuring GR for longer and GI and PG for shorter duration of germination favor the selection of breeding lines with adequate (moderate to high) resistance to pre-harvest sprouting. They noted that multiple measures over environments allowed identification of several QTL that would not have been revealed using a single time interval or measure of pre-harvest sprouting resistance. Although a number of the QTL they identified were unique to durum, most were reported in research on hexaploid wheat demonstrating the validity of their approach. They identified three highly significant QTL on chromosomes $1 \mathrm{~A}, 2 \mathrm{~B}$ and $7 \mathrm{~B}$ using a random inbred population of durum wheat. The complexity of pre-harvest sprouting resistance warrants a thorough examination of the trait from multiple perspectives for full elucidation of genetic factors.

QTL analysis is appropriate when multiple genes govern a trait i.e. complex genetic architecture. Identification and tagging of genetic loci is necessary for understanding the relationship among genes and the relationship with phenotype. Knox et al. (1998) performed genetic analysis of pre-harvest sprouting resistance on a white-seeded population of AC Karma and SC802 1-V2 in which AC Karma is moderately susceptible and SC8021-V2 is moderately resistant. They determined the segregation to be complex with at least seven effective factors involved. The present study with the same hexaploid wheat population is an extension of the previous study by Knox et al. (2012) in which GI, GR and PG measures were examined for three durations of germination counts in durum wheat. The objective of the present study was to maximize identification of QTL for pre-harvest sprouting resistance by analyzing three dormancy measures at multiple germination intervals across different environments.

\section{Materials and methods}

Mapping population

The SC8021-V2/AC Karma doubled haploid (DH) mapping population was derived from a cross between the Canada Prairie Spring (CPS) white wheat cultivar AC Karma (Knox et al. 1995), and the white-seeded germplasm line SC8021-V2 (DePauw et al. 1992). A population of $91 \mathrm{DH}$ lines were developed from the $\mathrm{F}_{1}$ plants using the maize pollination technique of Knox et al. (2000). The female parent, SC8021-V2 (PI554142), developed as a pre-harvest sprouting resistance line, has the pedigree Kenya-321/Peck. The male parent, AC Karma, with the pedigree HY320*5/ $8 \mathrm{~W} 553 / / \mathrm{HY} 35$, is moderately susceptible to preharvest sprouting.

\section{Field experiments}

Doubled haploid lines, SC8021-V2, AC Karma and three check lines AC Vista (DePauw et al. 1998), Genesis (HY355, DePauw et al. 1989) and RL4137 (DePauw et al. 2009) were grown in field trials near Swift Current and Saskatoon, Saskatchewan in 1997, 
1998 and 1999 in a randomized complete block design with three replications. Of the $91 \mathrm{DH}$ lines, 84 were grown in 1997 and 1998 near Swift Current and Saskatoon. AC Vista was not grown in 1997 and 1998 Swift Current, and Genesis was not grown in 1999 Saskatoon that contained 111 lines. Plots were one or two rows, 3 m long with 200 seeds per row. Rows were $23 \mathrm{~cm}$ apart and plots were separated by a row of spring-planted winter wheat that remained vegetative throughout the growing season to help control weeds and soil erosion, and to facilitate access for sampling. Five to ten spikes were harvested from each plot when half of the primary tillers had collapsed nodes on the stem that indicates about $16 \%$ grain moisture. Harvested spikes were air dried and then stored at $-20{ }^{\circ} \mathrm{C}$ in a freezer to preserve dormancy.

\section{Greenhouse experiment}

An alpha-lattice randomized complete block trial involving three replications that included the $91 \mathrm{DH}$ lines was conducted in a greenhouse $(\mathrm{GH})$ near Swift Current in 2004. The DH lines, parents and check lines RL4137, Genesis and AUS1408 (Mares 1987) were seeded in early spring 2004 and grown at temperature $20 \pm 5{ }^{\circ} \mathrm{C}$ with a long day photoperiod of $16 \mathrm{~h}$. Due to early sowing, plants reached physiological maturity in long natural day length with minimum use of supplemental light. The check cultivar AC Vista was not planted in the GH trial. To evaluate dormancy, two spikes per plant were harvested from each replication at physiological maturity. Harvested spikes were then ripened at $30{ }^{\circ} \mathrm{C}$ for 3 days and stored at $-20{ }^{\circ} \mathrm{C}$.

\section{Phenotypic evaluation}

The 5-10 spikes were threshed as a bulk for each experimental unit and seed germinations for evaluation with GI, GR and PG measures were performed as described by Knox et al. (2012) for each of the seven environments. The trait measures, environments (locations by year) and days on which germination data were assessed are presented in Fig. 1. The number of seeds plated was 41-51 in 1997, 13-72 in 1998 and 26-128 in 1999 for the trials near Saskatoon. Similarly for Swift Current, 31-60 seeds were plated in 1999. Due to an oversight, the number of seeds plated for

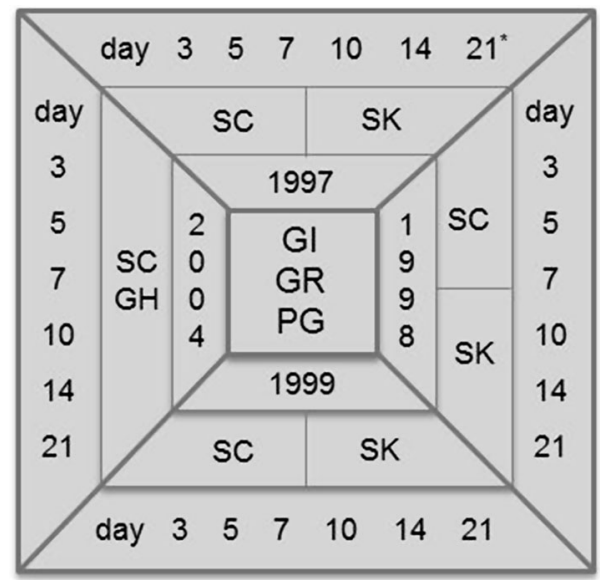

Fig. 1 Diagram of dormancy trait measures examined at different count durations in days from tests performed over multiple environments on 91 lines of the SC8021-V2/AC Karma doubled haploid mapping population where GI is germination index; GR: germination resistance, PG: percent germination, SC: Swift Current, SK: Saskatoon and GH: greenhouse. The asterisk indicates that data for PG at day 21 were not recorded for the SC and SK locations in 1997

Swift Current was not recorded during 1997 and 1998. In other tests there was little difference in number of viable seed and number of seed plated; therefore we used number of viable seed as totals for Swift Current 1997 and 1998. Seeds from the Swift Current trials were counted until day 28 in 1997 and day 21 in 1998 and 1999. For the Saskatoon trials, seeds were counted until day 28 in 1997 and 1998 and day 40 in 1999. The number of ungerminated seeds was recorded in 1997 , 1998 and moldy seeds was recorded in all the 3 years for Saskatoon. The number of ungerminated and moldy seeds was not recorded for Swift Current.

After the final counts for Swift Current 1999, the ungerminated seeds were treated with $4.0-6.0 \mathrm{ml}$ of $0.5 \mathrm{mM}$ gibberellic acid $\left(\mathrm{GA}_{3}\right)$ solution for $1 \mathrm{~h}$ to test the seeds viability as described by Knox et al. (2012). Daily counts of germinated seeds were recorded for another $3 \mathrm{~d}$. Any seed that failed to germinate was considered to be non-viable, and was excluded from the experimental total seeds. The measurements of seed germination for each DH line, parents and check lines were calculated as follows:

(i) Germination index (GI): GI (Reddy et al. 1985; Walker-Simmons 1988), places greater weight on seeds that germinate earlier and was calculated as: 
$\mathrm{GI}=\frac{\left\{d \times n_{1}+\left[(d-1) \times n_{2}\right]+\left[(d-2) \times n_{3}\right]+\cdots+\left[\left(1 \times n_{d}\right]\right\}\right.}{d \times N}$

where ' $d$ ' indicates the total number of days for which the seed was counted; $n_{1}, n_{2}, n_{3}, \ldots, n_{d}$ are the number of seeds germinated on the 1 st, 2 nd, 3 rd to $d$ th day and ' $N$ ' is the total number of viable seeds plated for germination. This equation of dormancy calculation provides a maximum index of 1.0 when all seeds germinate by day 1 , while an index of less than 1.0 indicates increased dormancy.

(ii) Germination resistance (GR): The equation of GR reported by Gordon (1971) calculates time when $50 \%$ of the seeds germinate:
PG. The PG21d (PG on day 21) was not determined for the 1997 Swift Current and Saskatoon environments (Fig. 1). The year-location combinations were abbreviated as follows: 1997SC, 1998SC, 1999SC and 2004SC-GH were field trials during 1997, 1998, 1999 and GH experiment during 2004 near Swift Current, respectively. Similarly 1997SK, 1998SK and 1999SK were field trials during 1997, 1998 and 1999 near Saskatoon, respectively.

$\mathrm{GR}=\frac{\left\{\left(\frac{d_{1}}{2}\right)\left(n_{1}\right)+\left[\left(\frac{d_{2}+d_{1}}{2}\right)\left(n_{2}\right)\right]+\left[\left(\frac{d_{3}+d_{2}}{2}\right)\left(n_{3}\right)\right]+\cdots+\left[\left(\frac{d_{i}+d_{i-1}}{2}\right)\left(n_{i}\right)\right]\right\}}{N}$ days

where $d_{1}, d_{2}, d_{3}, \ldots, d_{i}$ are the $1 \mathrm{st}, 2 \mathrm{nd}, 3 \mathrm{rd}$ to $i$ th day of the germination counts; $n_{1}, n_{2}, n_{3}, \ldots, n_{i}$ are the number of seeds that germinated on the 1 st, 2 nd, 3rd to $d_{i}$ th day, respectively and ' $N$ ' is the total number of seed germinated.

(iii) Percent germination (PG): PG was calculated as the number of seeds germinated on the day of interest divided by the total number of seed multiplied by 100 .

$\mathrm{PG}=\left(\frac{n}{N}\right) \times 100$

where ' $n$ ' is the cumulative number of seed germinated on the day the calculation was made and ' $N$ ' is the total number of viable seed.

To establish the effect of duration of the test on resolution of pre-harvest sprouting response, calculations for GI, GR and PG were performed at day 3, 5, 7, 10, 14 and 21, and respective measure-duration combinations were abbreviated as GI3d, GI5d, GI7d, GI10d, GI14d and GI21d for GI; GR3d, GR5d, GR7d, GR10d, GR14d and GR21d for GR; and similarly PG3d, PG5d, PG7d, PG10d, PG14d and PG21d for
Genotyping

Fresh young leaves $(2-5 \mathrm{~cm})$ of the parents and the 91 DH lines were sampled. DNA was extracted and simple sequence repeat (SSR) markers were applied as described by Knox et al. (2012). The markers used were those described by Somers et al. (2004).

Statistical analysis

GI, GR and PG results were analyzed using Statistical Analysis Software (SAS) version 8.2 (Littell et al. 1996). The diagnostic test rstudent (Rawlings 1988) was performed to identify outliers. The mixed model analysis of variance was performed on each environment with PROC MIXED. Genotypes were considered fixed and replications were random. Pearson's correlation $(r)$ was performed among sprouting measurement methods and within measurement methods for seed counts and durations of each test. The checks provided a reference with which to evaluate the performance of the measurement methods over DH lines of the SC8021-V2/AC Karma population. 
Linkage analysis, using JoinMap v4.1, was performed with 534 polymorphic SSR markers (Van Ooijen 2011). Those showing co-segregation were removed from further analysis. The Chi square goodness-of-fit test $(P \leq 0.01)$ implemented in JoinMap software was performed to test conformity to the expected Mendelian segregation ratio of 1:1. Markers showing segregation distortion from the expected ratio were excluded before grouping markers. The SSR markers were ordered with the regression mapping algorithm and were classified into linkage groups using a minimum LOD score threshold of 3.0 at an increment of 0.5. Linked markers were only considered as constituting a linkage group if more than five markers collapsed into a single group. The optimal marker order was estimated using the 'Ripple' command with a value of 1 . Recombination frequencies were converted to map distances in centimorgans (cM) using the Kosambi mapping function (Kosambi 1944).

QTL analysis on phenotypic measures was conducted using the linkage map and genotypic data of SSR markers from the $91 \mathrm{DH}$ lines. Composite interval mapping analysis was performed on the least square means data to determine the significant association of markers to traits using WinQTL Cartographer v2.5 (Wang et al. 2012). The ZmapQTL function with a window size of $10 \mathrm{cM}, 1 \mathrm{cM}$ walk speed and forward and backward regression of Standard Model 6 was used for QTL discovery. A significant QTL was declared when the LOD score was greater than the threshold value that was obtained based on a permutation test $(P \leq 0.05)$ using 1000 iterations independently for each trait. For this study, two QTL positions in the same linkage group were considered as a single QTL if the distance of the nearest marker of each QTL was $\leq 50 \mathrm{cM}$. We applied this definition of discrete QTL because QTL are marker-trait associations that vary among different datasets simply from random sampling variation. Therefore, it can be difficult to know which QTL in the same region among different data sets are a result of a common gene. QTL were accepted as novel if markers associated with QTL identified in this study did not coincide with markers reported in previous studies.

\section{Results}

Phenotypic evaluation

The mean values of the parents and check lines (from here on simply referred to as checks) for the three dormancy measures varied across multiple environments. Within each germination count duration interval, the checks showed significant variation in dormancy level (Supplementary Fig. 1a-c). RL4137 and SC8021-V2 were sprouting resistant; AC Vista was moderately resistant, while AC Karma and Genesis were the most susceptible throughout the study. In each year of field trials, lower dormancy was observed at Saskatoon compared to the Swift Current trials (Supplementary Fig. 1a-c). The ranking from sprouting resistant to sprouting susceptible was consistent with previously published results (Knox et al. 2012).

GI discriminated among the less dormant genotypes in a short germination test, such as 3 days (GI3d), but discriminated better among more dormant genotypes if the test was run longer, such as 14 days (GI14d). For instance, AC Karma had a GI of 0.72 after 3 days, but SC8021-V2 needed more than $14 \mathrm{~d}$ to achieve an equivalent germination in the Swift Current trial of 1997 (Supplementary Fig. 1a). Moreover, dormant RL4137 required more than 3 weeks to reach a comparable GI. A similar trend for GI was observed in all field environments, but not with the $\mathrm{GH}$ environment where relatively low discrimination between genotypes was observed. Both AC Karma and SC8021-V2 showed no germination within the GH trial assessed on the 3rd day (GI3d $=0.00)$; however, AC Karma germinated more quickly than SC8021-V2 with increasing number of days.

GR tended to discriminate between genotypes the longer the seeds were germinated, which was more apparent for the highly dormant genotypes. For example, lines were more differentiated at GR21d compared to GR3d (Supplementary Fig. 1b). AC Karma, in all the field environments, showed a consistently low resistance to germination $(\mathrm{GR} 21 \mathrm{~d}=2.07)$, which means it germinated quickly, while SC8021-V2 germinated less quickly and exhibited a higher GR $($ GR $21 \mathrm{~d}=5.85)$ (Supplementary Fig. 1b). 
PG did not discriminate effectively among genotypes with low dormancy, but differentiated among genotypes with greater dormancy and those with short to moderate durations of 3-7d. Clear differences were observed between dormant and non-dormant genotypes using the PG measure; Genesis and AC Karma both exhibited rapid germination by day 3 $(\mathrm{PG} 3 \mathrm{~d}=96 \%)$ whereas RL4137 $(\mathrm{PG} 3 \mathrm{~d}=0.00)$ and SC8021-V2 $(\mathrm{PG} 3 \mathrm{~d}=14 \%)$ showed greatest resistance to germination (Supplementary Fig. 1c). SC8021-V2 germinated earlier than RL4137 and this difference was best observed at days 5 and 7 . In contrast, PG was a poor measure for genotypes possessing greater dormancy if germination continued for a longer duration. For example, the dormant parent SC8021-V2 had the same PG (96\%) by day 14 as AC Karma had on day 3 in 1997 near Swift Current. Unlike field trials, germination among genotypes when tested in the GH trial continued to show some variation for more dormant lines at longer germination durations. Maximum difference between less dormant and dormant genotypes was observed with measures GI5d, GR21d and PG5d for field environments and GI10d, GR21d and PG7d for the GH environment.

Frequency distributions of GI, GR and PG by germination time intervals (Supplementary Fig. 2a-l) revealed that the lines were commonly skewed with the peak positioned over the less dormant portion of the distribution; although normal-shaped and bimodal distributions were also observed, mostly for intermediate durations of germination. Bi-directional transgressive segregation was evident across environments and types of measure-durations; however, transgressive genotypes varied. Depending on the environment, a differential in germination rate was higher at an earlier or later duration. For example, in 1999SC the greatest differential in PG occurred at days 3 and 5, whereas the differential was greatest for PG7d in the $2004 \mathrm{GH}$.

Correlations (Supplementary Table 1) within environments among trait germination measure-durations tended to show a reduced relationship among and within measures for more disparate germination durations. The range in correlation coefficient between GI and PG among germination durations varied from 0.38 to 0.99 for field, whereas a slightly greater range of 0.17-0.99 was observed among measures associated with the GH environments. The GI and GR were negatively correlated with a maximum range of -0.43 to -1.00 for field and again a greater range of -0.18 to -0.98 for the GH trials. The negative correlations between PG and GR measures ranged from -0.37 to -0.97 with field environments and -0.22 to -0.98 with the GH environments.

Genetic map and QTL for pre-harvest sprouting resistance

The SC8021-V2/AC Karma genetic map of SSR markers consisted of 485 loci distributed over 24 linkage groups covering $1411.5 \mathrm{cM}$ (Supplementary Table 2). The remaining 49 SSRs either showed segregation distortion or remained ungrouped and hence were excluded from the map. The order of the markers resembled the wheat microsatellite consensus genetic map published by Somers et al. (2004). Two linkage groups were associated with each of chromosomes $1 \mathrm{~A}, 7 \mathrm{~A}$ and 7D and were labelled as $1 \mathrm{~A} 1$ and 1A2, 7A1 and 7A2, and 7D1 and 7D2 (Fig. 2).

The genome-wide significant LOD thresholds for QTL declaration obtained by the 1000 iterations for each data set ranged from 2.08 to 3.97 at $p \leq 0.05$. At these thresholds, 33 chromosomal regions were associated with pre-harvest sprouting resistance, of which the six chromosomes 2B, 2D, 3A, 4A, 4D and 6D exhibited more than one QTL peak that were within $50 \mathrm{cM}$ of each other. Each QTL is listed with the associated chromosome arm, environment-measureduration, associated marker-interval, LOD values of QTL peak, percent phenotypic variation explained (\% PVE), and favorable parental allele in Table 1 . The QTL on the same chromosome within $50 \mathrm{cM}$ of each other were considered as one and designated by a common name giving a total of 26 QTL and representing all 21 wheat chromosomes (Fig. 2). However, three chromosomes namely 3D, 7B and 7D1 each contained two QTL peaking more than $50 \mathrm{cM}$ from one another and were considered separate QTL. In this case, the QTL were designated $Q P h s . s p a-$ 3D.1, QPhs.spa-3D.2; QPhs.spa-7B.1, QPhs.spa-7B.2 and QPhs.spa-7D1.1, QPhs.spa-7D1.2 (Fig. 2; Table 1). All seven environments (six field and one $\mathrm{GH}$ ) for all three measures by six germination durations, except for the GI measure from the 1998 Saskatoon environment, were involved in revealing the 26 QTL.

The explained portion of phenotypic variation for the QTL ranged from minor, with a low of $6 \%$, to 
$1 \mathrm{~A} 1$

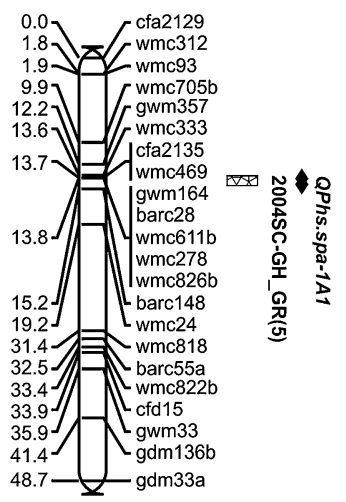

$1 \mathrm{~A} 2$
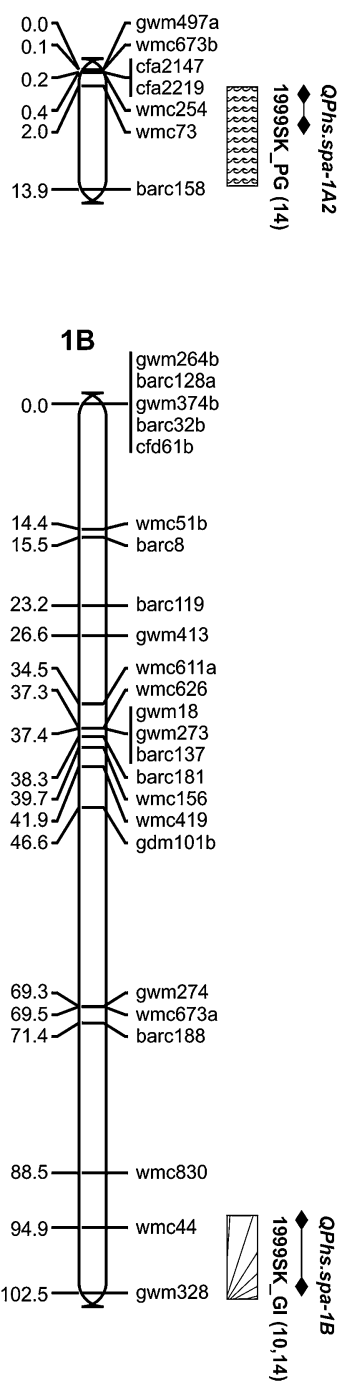

1D

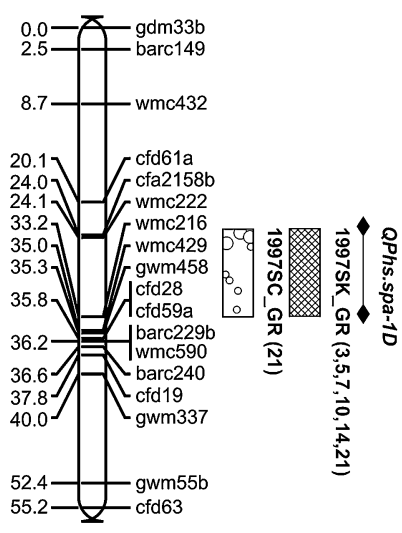

2B

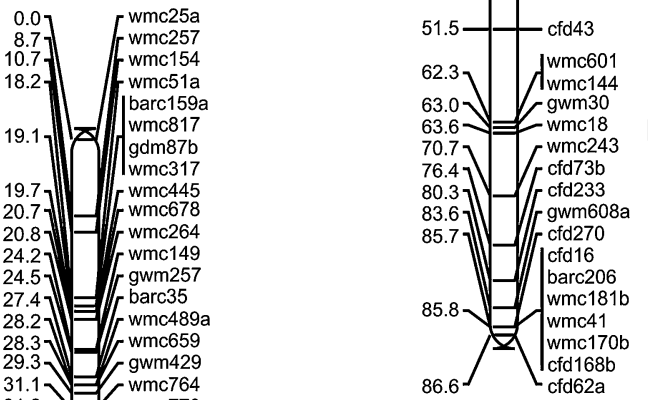

$31.2 \mathrm{~W}$ wmc770

$31.8 \longrightarrow$ wmc382b

14.3 $=1$ barc7

E barc13

34.6

=

ב

ע. Wmc477

38.9 .

gwm630
gwm319

gwm319
barc167

$39.1-\mathrm{cfa} 2278$

39.2 - wmc592

- wmc661

- wmc102

gwm55a

- gwm55a

- gwm388

wmc546

- barc101

- wmc441

gwm120
cfd73a

wmc175

wmc175
wmc332
2A

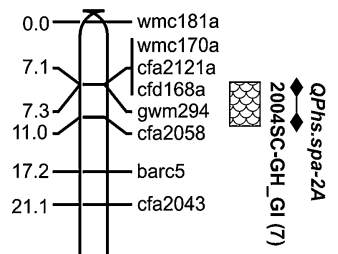

2D

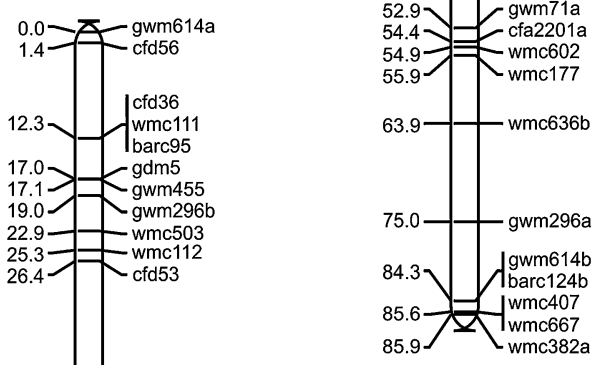


4Fig. 2 Genetic map of the SC8021-V2/AC Karma doubled haploid $(\mathrm{DH})$ mapping population showing twenty one wheat chromosomes (represented by twenty four linkage groups) and the location of 26 QTL significantly $(P \leq 0.05)$ associated with dormancy (i.e. pre-harvest sprouting resistance) based on multiple measures and durations on $91 \mathrm{DH}$ lines. Markers and QTL are indicated on the right and their positions $(\mathrm{cM})$ are indicated on the left side of each linkage group. Common SSR markers mapped and identified homoeologous QTL on chromosomes 4A, 4B and 4D are underlined. QTL intervals are represented by pattern filled rectangular boxes. Each QTL was defined by year, location, measurement and day interval on which QTL was detected where SC: Swift Current, SK: Saskatoon, GH: greenhouse, GI: germination index, GR: germination resistance, PG: percent germination

major, with a high of $60 \%$. Nineteen QTL were specific to field environments, three were detected in the GH environment only, and four were common in both GH and field environments. Five QTL were identified with GI and PG, seven QTL with GR and PG, and four QTL with GI, GR and PG measures (Fig. 3). The same QTL were not detected for both GI and GR measures in this study. Based on individual trait measures, three QTL each were identified with GI and with GR and four QTL were identified with PG (Fig. 3). Across experiments, the number of QTL associated with each germination measure-duration and associated chromosome broken down by year, location, trait measure, and the day of germination is summarized in Table 2. A total of 125 measureduration combinations contributed to detection of the 26 QTL. For example, a maximum of 31 measuredurations involving GI, GR and PG identified a QTL on chromosome 5D, while 12 identified a QTL on 4B, 11 on 7D, and 10 on 2B (Table 2).

QPhs.spa-5D, a consistent and major QTL observed through dormancy measures GI, GR and PG, was identified on chromosome 5D at SSR locus $g d m 133 b$. Except for 1999SC, this QTL was detected in each environment and explained 11-29\% of the phenotypic variation of the traits measured (Tables 1 , 2; Fig. 2). The QPhs.spa-5D allele for greater seed dormancy was contributed by SC8021-V2, the parent with greater seed dormancy. Another consistent QTL, QPhs.spa-2B on chromosome 2B observed with GI, GR, and PG was detected in 1998SK, 1999SK and 2004SC-GH trials. Although two LOD peaks were observed for this QTL, they were considered as a single QTL because they differed by merely $4 \mathrm{cM}$.
QPhs.spa-2B had a moderate effect, compared to QPhs.spa-5D, explaining 8-16\% of the variation. SC8021-V2 contributed the QPhs.spa-2B greater seed dormancy allele. Two other QTL, one on chromosome 2D (QPhs.spa-2D) and the other on 6D (QPhs.spa$6 D)$, produced moderate effects and were detected with the $\mathrm{GH}$ and at least one field environment. The resistant alleles for both of these QTL came from dormant parent, SC8021-V2.

Other QTL detected in response of reduced GI and $\mathrm{PG}$ measures were mapped on chromosomes 2D, 4B, 7A2 (resistant allele contributed by SC8021-V2), 4D and 7D2 (resistant allele contributed by AC Karma) (Figs. 2, 3). QPhs.spa-2D was observed as three peaks associated with different environments within the $8.2 \mathrm{cM}$ interval of wmc144-wmc243.

In the field environments, GI at three durations of germination and PG at all six durations identified a major QTL, QPhs.spa-4B, which was mapped on chromosome 4B in marker interval wmc617b-wmc48a that spanned $11.6 \mathrm{cM}$. This QTL, with resistance from SC8021-V2, explained 35-60\% of the phenotypic variation. Another major QTL, QPhs.spa-7D2, observed with GI and PG in field environments was revealed on chromosome $7 \mathrm{D} 2$ in a $4 \mathrm{cM}$ region flanked by barc76 and cfa2257a. QPhs.spa-7D2 explained 14-47\% of the phenotypic variation, and the resistance came from AC Karma. A QTL, QPhs.s$p a-4 A$, was specific to the 1999SC trial and was observed on chromosome 4A with GI5d, and GR and PG at multiple durations. QPhs.spa-4A was identified as two peaks that differed by $12 \mathrm{cM}$ in marker intervals barc170-wmc617a. AC Karma contributed the resistance of QPhs.spa-4A, and this source explained $17-33 \%$ of the phenotypic variation. Quantitative trait locus, QPhs.spa-1D, on chromosome 1D was observed with GR21d in 1997SC and GR3-21d in 1997SK. This QTL explained 30-44 \% of the phenotypic variation and resistance was contributed by SC8021-V2.

The marker wmc617 amplified DNA in all three homoeologous group four chromosomes. QPhs.spa$4 A$ was detected in interval barc170-gwm397-wmc617a on chromosome 4A, QPhs.spa-4B was detected in the interval wmc617b-wmc 48 on chromosome $4 \mathrm{~B}$ and QPhs.spa-4D was detected in interval wmc617c$w m c 89 b$ on chromosome 4D. QPhs.spa-4B had largest effect explaining up to $60 \%$ of the phenotypic 


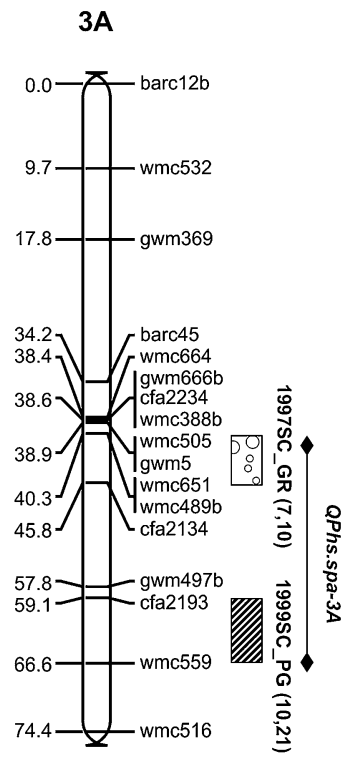

3B

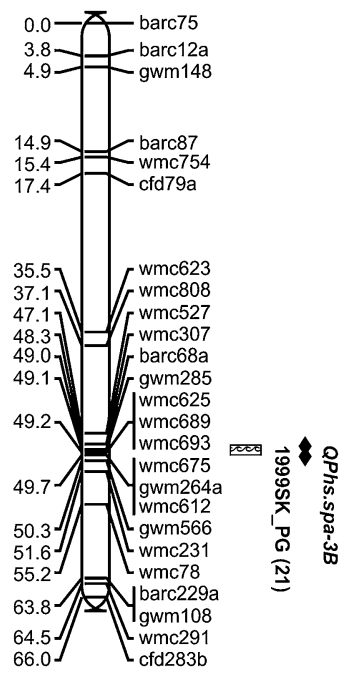

3D

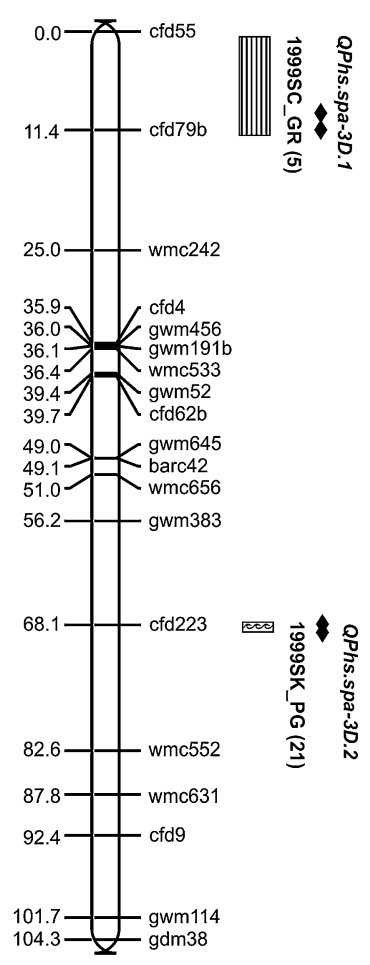

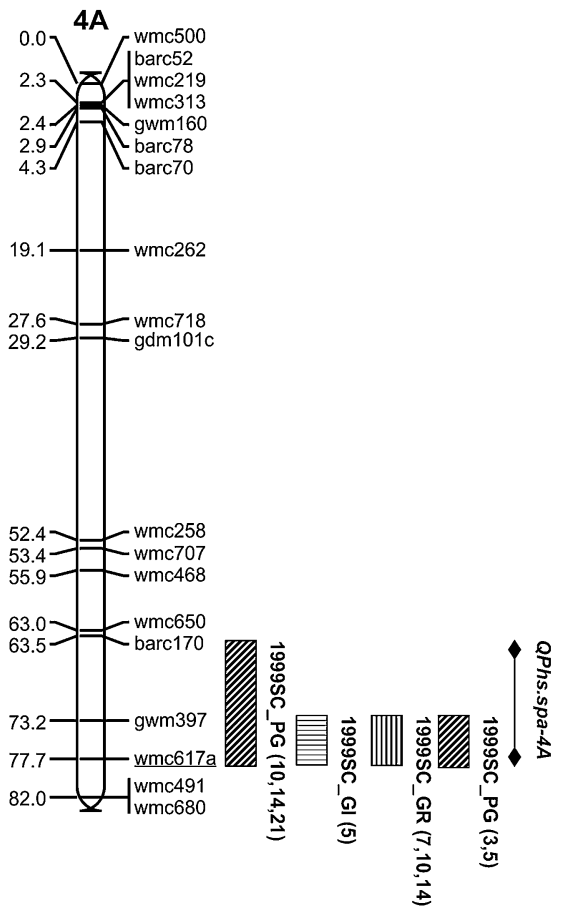

4D

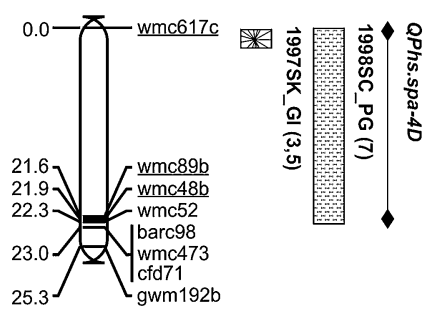

4B

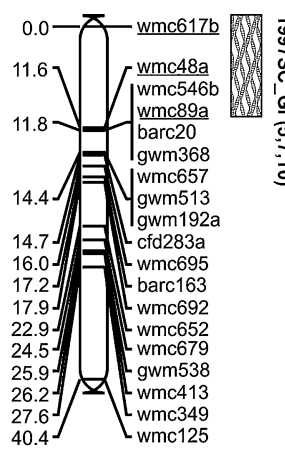

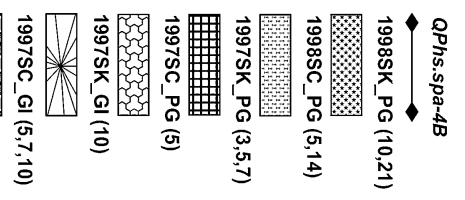

Fig. 2 continued

variation. Other QTL observed in the SC8021-V2/AC Karma DH population had minor to moderate effects for GI, GR and PG measures at various durations (Table 1; Fig. 2).

\section{Discussion}

No previous reports were found for the six QTL mapped on chromosomes 1B, 2D, 5D, 6A, 7D1.2 and 
5A

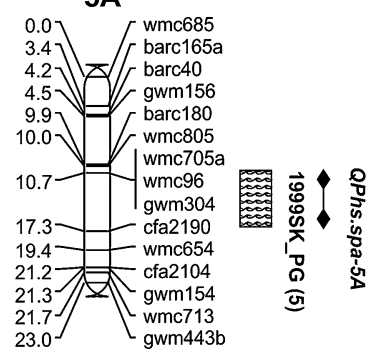

5B

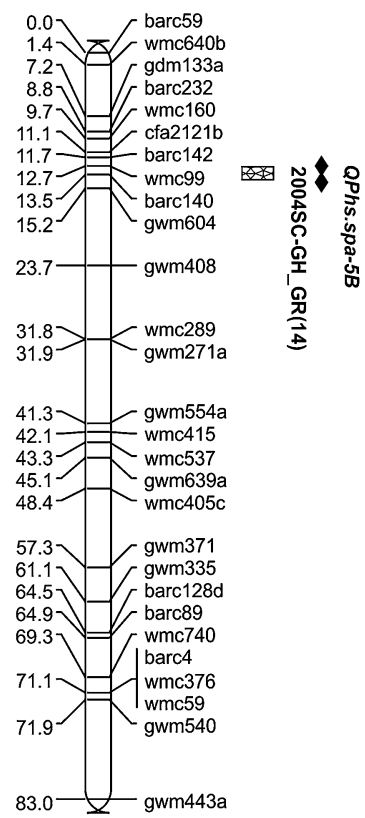

6A

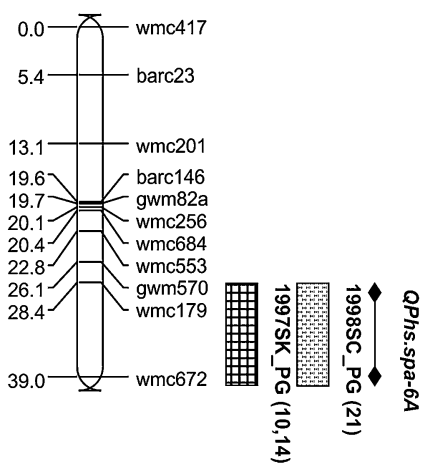

Fig. 2 continued
5D

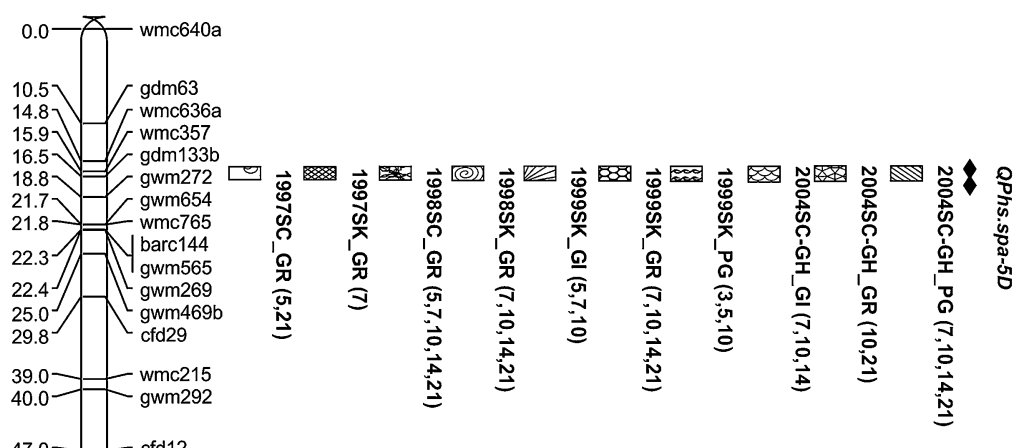

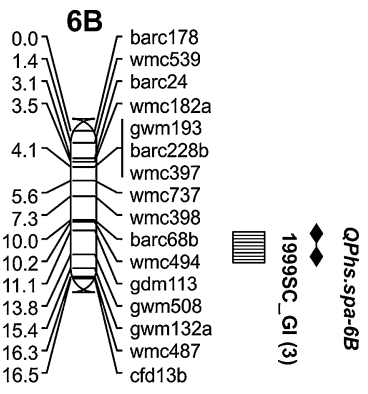

6D

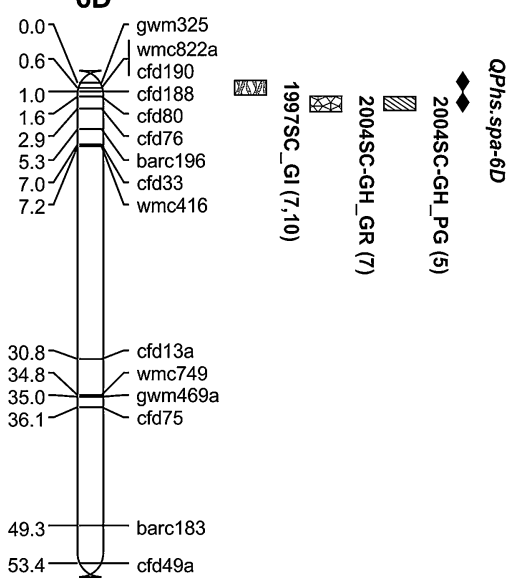


7A1

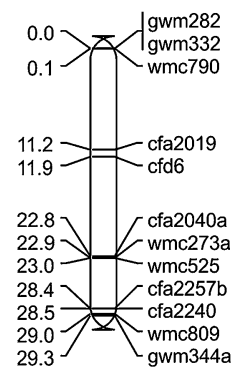

7A2

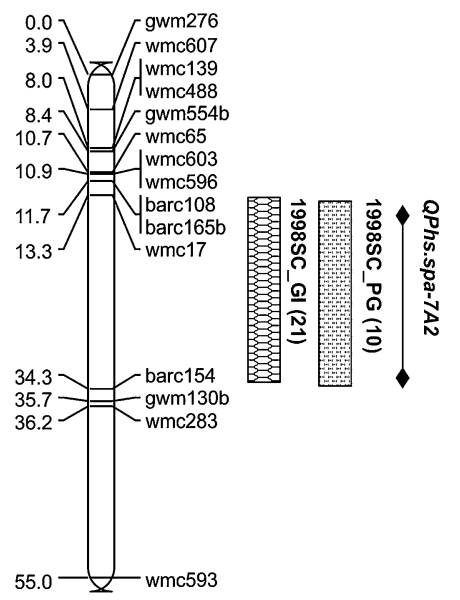

7B

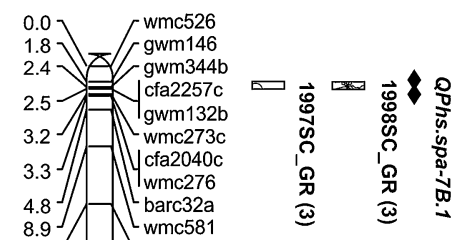

7D1

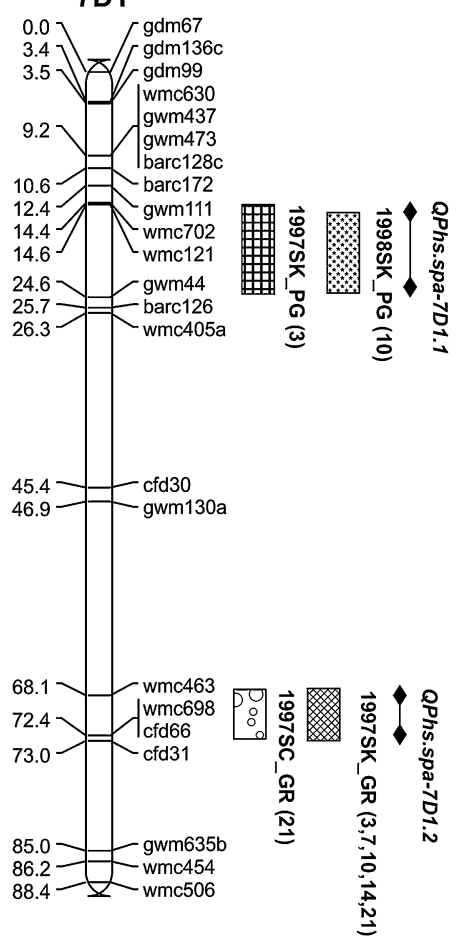

7D2

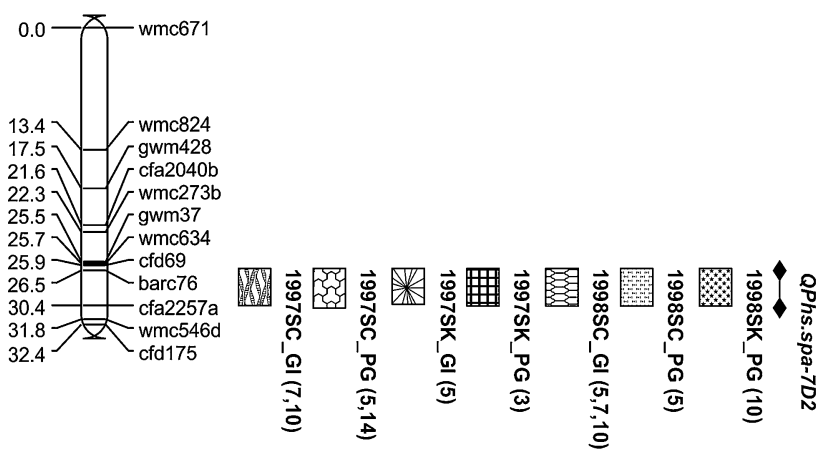

Fig. 2 continued

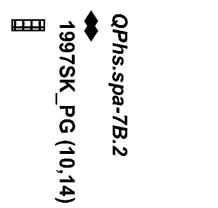


Table 1 Significant QTL for dormancy (i.e. pre-harvest sprouting resistance) measurement methods and durations across environments using composite interval mapping

\begin{tabular}{|c|c|c|c|c|c|c|c|}
\hline $\begin{array}{l}\text { QTL year/ } \\
\text { location }\end{array}$ & $\begin{array}{l}\text { Trait measure and } \\
\text { duration (in days) }\end{array}$ & $\begin{array}{l}\text { Chromosome } \\
\operatorname{arm}^{\mathrm{a}}\end{array}$ & $\begin{array}{l}\text { QTL associated } \\
\text { marker-interval }^{\mathrm{b}}\end{array}$ & $\begin{array}{l}\text { LOD } \\
\text { threshold }^{c}\end{array}$ & CIM LOD ${ }^{d}$ & $\% \mathrm{PVE}^{\mathrm{e}}$ & $\begin{array}{l}\text { Additive } \\
\text { value }^{\text {f }}\end{array}$ \\
\hline \multicolumn{8}{|c|}{ QPhs.spa-1A1 (SC8021-V2) ${ }^{\mathrm{g}}$} \\
\hline $\begin{array}{c}\text { 2004/SC- } \\
\text { GH }\end{array}$ & GR5 & $1 \mathrm{AL}$ & cfa2135 & 3.54 & 3.60 & 6 & 0.10 \\
\hline \multicolumn{8}{|c|}{ QPhs.spa-1A2 (SC8021-V2) } \\
\hline 1999/SK & PG14 & $1 \mathrm{AL}$ & wmc73-barc158 & 2.78 & 4.97 & 25 & -0.52 \\
\hline \multicolumn{8}{|c|}{ QPhs.spa-1B (SC8021-V2) } \\
\hline 1999/SK & GI10,14 & $1 \mathrm{BL}$ & wmc44-gwm328 & $3.08-3.23$ & $3.59-3.63$ & 18 & -0.03 \\
\hline \multicolumn{8}{|c|}{ QPhs.spa-1D (SC8021-V2) } \\
\hline 1997/SC & GR21 & 1DS & wmc222-wmc216 & 2.93 & 6.58 & 37 & 1.14 \\
\hline 1997/SK & GR3-21 & 1DS & wmc222-wmc216 & $2.90-3.08$ & $3.76-6.76$ & $30-44$ & $0.62-0.74$ \\
\hline \multicolumn{8}{|c|}{ QPhs.spa-2A (AC Karma) } \\
\hline $\begin{array}{c}\text { 2004/SC- } \\
\text { GH }\end{array}$ & GI7 & $2 \mathrm{AL}$ & gwm294-cfa2058 & 3.19 & 3.92 & 13 & 0.04 \\
\hline \multicolumn{8}{|c|}{ QPhs.spa-2B (SC8021-V2) } \\
\hline $\begin{array}{l}\text { 2004/SC- } \\
\text { GH }\end{array}$ & GI21 & $2 \mathrm{BL}$ & wmc546c & 2.82 & 3.72 & 9 & -0.05 \\
\hline 1998/SK & GR3,7,10 & $2 \mathrm{BL}$ & gwm55a & $3.23-3.31$ & $3.89-4.97$ & $13-16$ & $0.28-0.41$ \\
\hline 1999/SK & GR7,21 & $2 \mathrm{BL}$ & wmc546c & $3.25-3.50$ & $3.37-4.04$ & $11-13$ & $0.21-0.25$ \\
\hline 1999/SK & PG3 & $2 \mathrm{BL}$ & wmc546c & 3.44 & 3.67 & 12 & -6.53 \\
\hline $\begin{array}{l}\text { 2004/SC- } \\
\text { GH }\end{array}$ & PG10-21 & $2 \mathrm{BL}$ & wmc546c & $2.58-2.99$ & $3.37-3.52$ & $8-10$ & $\begin{array}{c}-5.83 \text { to } \\
-6.85\end{array}$ \\
\hline \multicolumn{8}{|c|}{ QPhs.spa-2D (SC8021-V2) } \\
\hline 1999/SC & $\mathrm{GI} 14,21$ & $2 \mathrm{DL}$ & $\underline{\text { wmc18-wmc243 }}$ & $3.09-3.40$ & $3.89-4.95$ & $13-14$ & -0.07 \\
\hline 1999/SC & PG7,10,21 & & $\underline{w m c 18}$ & $3.00-3.39$ & $2.97-4.91$ & $9-14$ & $\begin{array}{c}-3.49 \text { to } \\
-7.45\end{array}$ \\
\hline $\begin{array}{l}\text { 2004/SC- } \\
\text { GH }\end{array}$ & PG5 & $2 \mathrm{DL}$ & $\underline{\text { wmc144 }}$ & 2.21 & 8.41 & 43 & -19.27 \\
\hline \multicolumn{8}{|c|}{ QPhs.spa-3A (SC8021-V2) } \\
\hline 1997/SC & GR7,10 & $3 \mathrm{AL}$ & wmc489b-cfa2134 & $2.89-2.98$ & $4.05-4.72$ & $25-30$ & $1.28-1.81$ \\
\hline \multicolumn{8}{|c|}{ QPhs.spa-3A (AC Karma) } \\
\hline 1999/SC & PG10,21 & $3 \mathrm{AL}$ & cfa2193-wmc559 & $2.43-3.00$ & $3.65-5.42$ & $24-25$ & $8.91-13.71$ \\
\hline \multicolumn{8}{|c|}{ QPhs.spa-3B (AC Karma) } \\
\hline 1999/SK & PG21 & $3 \mathrm{BL}$ & $\underline{\text { wmc307 }}$ & 2.08 & 2.22 & 8 & 0.09 \\
\hline \multicolumn{8}{|c|}{ QPhs.spa-3D.1 (AC Karma) } \\
\hline 1999/SC & GR5 & 3DS & cfd55-cfd79b & 3.77 & 5.78 & 23 & -0.36 \\
\hline \multicolumn{8}{|c|}{ QPhs.spa-3D.2 (SC8021-V2) } \\
\hline 1999/SK & PG21 & $3 \mathrm{DL}$ & $\underline{\operatorname{cfd} 223}$ & 2.08 & 2.82 & 10 & -0.09 \\
\hline \multicolumn{8}{|c|}{ QPhs.spa-4A (AC Karma) } \\
\hline 1999/SC & GI5 & $4 \mathrm{AL}$ & gwm397-wmc617a & 3.91 & 4.84 & 17 & 0.13 \\
\hline $1999 / \mathrm{SC}$ & GR7-14 & $4 \mathrm{AL}$ & gwm397-wmc617a & $3.72-3.83$ & $4.62-5.31$ & $17-25$ & $\begin{array}{c}-0.56 \text { to } \\
-0.83\end{array}$ \\
\hline 1999/SC & PG3,5,10-21 & $4 \mathrm{AL}$ & barc170-wmc617a & $2.43-3.97$ & $3.22-5.22$ & $19-33$ & $8.96-14.69$ \\
\hline \multicolumn{8}{|c|}{ QPhs.spa-4B (SC8021-V2) } \\
\hline $1997 / \mathrm{SC}$ & GI5-10 & $4 \mathrm{BL}$ & wmc617b-wmc48a & 3.07 & 4.50 & 35 & -0.26 \\
\hline 1997/SK & GI10 & $4 \mathrm{BL}$ & wmc617b-wmc48a & 2.86 & 15.57 & 56 & -0.45 \\
\hline
\end{tabular}


Table 1 continued

\begin{tabular}{|c|c|c|c|c|c|c|c|}
\hline $\begin{array}{l}\text { QTL year/ } \\
\text { location }\end{array}$ & $\begin{array}{l}\text { Trait measure and } \\
\text { duration (in days) }\end{array}$ & $\begin{array}{l}\text { Chromosome } \\
\operatorname{arm}^{\mathrm{a}}\end{array}$ & $\begin{array}{l}\text { QTL associated } \\
\text { marker-interval }^{\text {b }}\end{array}$ & $\begin{array}{l}\text { LOD } \\
\text { threshold }^{c}\end{array}$ & CIM LOD ${ }^{\mathrm{d}}$ & $\% \mathrm{PVE}^{\mathrm{e}}$ & $\begin{array}{l}\text { Additive } \\
\text { value }^{f}\end{array}$ \\
\hline 1997/SC & PG5 & 4BL & wmc617b-wmc48a & 2.96 & 10.11 & 48 & -43.80 \\
\hline 1997/SK & PG3-7 & $4 \mathrm{BL}$ & wmc617b-wmc48a & $2.75-3.03$ & $7.80-17.57$ & $45-59$ & $\begin{array}{c}-40.29 \text { to } \\
-48.63\end{array}$ \\
\hline 1998/SC & PG5,14 & $4 \mathrm{BL}$ & wmc617b-wmc48a & 2.85 & $9.81-17.89$ & $50-60$ & $\begin{array}{c}-45.20 \text { to } \\
-49.10\end{array}$ \\
\hline 1998/SK & PG10,21 & $4 \mathrm{BL}$ & wmc617b-wmc48a & 2.99 & $17.06-18.69$ & $54-56$ & $\begin{array}{c}-46.51 \text { to } \\
-47.82\end{array}$ \\
\hline \multicolumn{8}{|c|}{ QPhs.spa-4D (AC Karma) } \\
\hline 1997/SK & GI3,5 & 4DS & wmc617c & $2.82-3.04$ & $3.22-3.28$ & $10-12$ & $0.09-0.10$ \\
\hline 1998/SC & PG7 & 4DS & wmc617c-wmc89b & 2.91 & 8.55 & 42 & 43.31 \\
\hline \multicolumn{8}{|c|}{ QPhs.spa-5A (SC8021-V2) } \\
\hline 1999/SK & PG5 & $5 \mathrm{AS}$ & gwm304-cfa2190 & 3.12 & 4.33 & 18 & -3.63 \\
\hline \multicolumn{8}{|c|}{ QPhs.spa-5B (SC8021-V2) } \\
\hline $\begin{array}{l}\text { 2004/SC- } \\
\text { GH }\end{array}$ & GR14 & $5 \mathrm{BL}$ & $\underline{\text { wmc99 }}$ & 3.15 & 4.99 & 11 & 0.44 \\
\hline \multicolumn{8}{|c|}{ QPhs.spa-5D (SC8021-V2) } \\
\hline 1999/SK & GI5-10 & $5 \mathrm{DL}$ & $\underline{\operatorname{gdm} 133 \mathrm{~b}}$ & $3.08-3.51$ & $3.83-4.05$ & 13 & -0.05 \\
\hline $\begin{array}{l}\text { 2004/SC- } \\
\text { GH }\end{array}$ & GI7-14 & $5 \mathrm{DL}$ & $\underline{\operatorname{gdm} 133 \mathrm{~b}}$ & $3.09-3.27$ & $6.27-10.81$ & $16-29$ & $\begin{array}{l}-0.04 \text { to } \\
-0.08\end{array}$ \\
\hline 1997/SC & GR5,21 & $5 \mathrm{DL}$ & $\underline{\operatorname{gdm} 133 \mathrm{~b}}$ & $2.93-2.98$ & $3.63-4.35$ & $12-18$ & $0.41-0.89$ \\
\hline 1997/SK & GR7 & $5 \mathrm{DL}$ & $\underline{\operatorname{gdm} 133 \mathrm{~b}}$ & 3.08 & 3.27 & 11 & 0.57 \\
\hline 1998/SC & GR5-21 & $5 \mathrm{DL}$ & $\underline{\operatorname{gdm} 133 \mathrm{~b}}$ & $3.05-3.27$ & $3.89-5.29$ & $14-18$ & $0.42-0.81$ \\
\hline 1998/SK & GR7-21 & $5 \mathrm{DL}$ & $\underline{\operatorname{gdm} 133 \mathrm{~b}}$ & $3.14-3.38$ & $4.23-6.08$ & $14-19$ & $0.33-059$ \\
\hline 1999/SK & GR7-21 & $5 \mathrm{DL}$ & $\underline{\operatorname{gdm} 133 \mathrm{~b}}$ & $3.25-3.50$ & $3.93-4.51$ & $13-15$ & $0.21-0.27$ \\
\hline $\begin{array}{l}\text { 2004/SC- } \\
\text { GH }\end{array}$ & GR10,21 & $5 \mathrm{DL}$ & $\underline{\operatorname{gdm} 133 \mathrm{~b}}$ & $3.19-3.21$ & $4.51-6.91$ & $11-17$ & $0.41-0.53$ \\
\hline 1999/SK & PG3,5,10 & $5 \mathrm{DL}$ & $\underline{\operatorname{gdm} 133 \mathrm{~b}}$ & $2.85-3.44$ & $3.37-5.23$ & $12-18$ & $\begin{array}{c}-0.41 \text { to } \\
-6.88\end{array}$ \\
\hline $\begin{array}{l}\text { 2004/SC- } \\
\text { GH }\end{array}$ & PG7-21 & $5 \mathrm{DL}$ & $\underline{\operatorname{gdm} 133 \mathrm{~b}}$ & $2.58-3.51$ & $7.23-8.31$ & $20-25$ & $\begin{array}{r}-9.20 \text { to } \\
-14.34\end{array}$ \\
\hline \multicolumn{8}{|c|}{ QPhs.spa-6A (AC Karma) } \\
\hline 1997/SK & PG10,14 & $6 \mathrm{AL}$ & wmc179-wmc672 & 2.83 & 7.34 & 50 & 47.43 \\
\hline 1998/SC & PG21 & $6 \mathrm{AL}$ & wmc179-wmc672 & 2.86 & 8.23 & 52 & 46.73 \\
\hline \multicolumn{8}{|c|}{ QPhs.spa-6B (SC8021-V2) } \\
\hline 1999/SC & GI3 & $6 \mathrm{BS}$ & 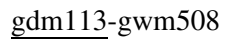 & 3.90 & 5.00 & 25 & -0.16 \\
\hline \multicolumn{8}{|c|}{ QPhs.spa-6D (SC8021-V2) } \\
\hline 1997/SC & GI7,10 & $6 \mathrm{D}$ & $\underline{\text { gwm } 325}$ & $2.83-2.98$ & 3.04 & 15 & -0.28 \\
\hline $\begin{array}{l}\text { 2004/SC- } \\
\text { GH }\end{array}$ & GR7 & $6 \mathrm{D}$ & $\underline{\operatorname{cfd} 80}$ & 3.03 & 4.04 & 10 & 0.14 \\
\hline $\begin{array}{l}\text { 2004/SC- } \\
\text { GH }\end{array}$ & PG5 & $6 \mathrm{D}$ & $\underline{\operatorname{cfd} 80}$ & 2.21 & 2.60 & 8 & -3.27 \\
\hline \multicolumn{8}{|c|}{ QPhs.spa-7A2 (SC8021-V2) } \\
\hline 1998/SC & GI21 & 7AS & wmc17-barc154 & 2.81 & 4.60 & 48 & -0.39 \\
\hline 1998/SC & PG10 & 7AS & wmc17-barc154 & 2.90 & 5.95 & 49 & -40.91 \\
\hline \multicolumn{8}{|c|}{ QPhs.spa-7B.1 (SC8021-V2) } \\
\hline 1997/SC & GR3 & $7 \mathrm{BL}$ & gwm146-gwm344b & 2.80 & 2.92 & 13 & 0.60 \\
\hline
\end{tabular}


Table 1 continued

\begin{tabular}{|c|c|c|c|c|c|c|c|}
\hline $\begin{array}{l}\text { QTL year/ } \\
\text { location }\end{array}$ & $\begin{array}{l}\text { Trait measure and } \\
\text { duration (in days) }\end{array}$ & $\begin{array}{l}\text { Chromosome } \\
\operatorname{arm}^{\mathrm{a}}\end{array}$ & $\begin{array}{l}\text { QTL associated } \\
\text { marker-interval }^{\text {b }}\end{array}$ & $\begin{array}{l}\text { LOD } \\
\text { threshold }^{\mathrm{c}}\end{array}$ & CIM LOD ${ }^{\mathrm{d}}$ & $\% \mathrm{PVE}^{\mathrm{e}}$ & $\begin{array}{l}\text { Additive } \\
\text { value }^{f}\end{array}$ \\
\hline 1998/SC & GR3 & $7 \mathrm{BL}$ & gwm146-gwm344b & 3.02 & 3.10 & 12 & 0.27 \\
\hline \multicolumn{8}{|c|}{ QPhs.spa-7B.2 (SC8021-V2) } \\
\hline 1997/SK & PG10,14 & $7 \mathrm{~B}$ & $\underline{w m c 405 b}$ & 2.83 & 3.32 & 13 & -12.59 \\
\hline \multicolumn{8}{|c|}{ QPhs.spa-7D1.1 (SC8021-V2) } \\
\hline 1997/SK & PG3 & 7DS & wmc121-gwm44 & 3.03 & 8.99 & 48 & -39.18 \\
\hline 1998/SK & PG10 & 7DS & wmc121-gwm44 & 2.99 & 14.54 & 55 & -44.85 \\
\hline \multicolumn{8}{|c|}{ QPhs.spa-7D1.2 (AC Karma) } \\
\hline 1997/SC & GR21 & 7DS & wmc463-wmc698 & 2.93 & 4.61 & 21 & -0.87 \\
\hline 1997/SK & GR3,7-21 & 7DS & wmc463-wmc698 & $2.90-3.08$ & $5.23-5.75$ & $22-27$ & $\begin{array}{c}-0.55 \text { to } \\
-0.63\end{array}$ \\
\hline \multicolumn{8}{|c|}{ QPhs.spa-7D2 (AC Karma) } \\
\hline 1997/SC & GI7,10 & $7 \mathrm{DL}$ & $\underline{\text { barc76-cfa2257a }}$ & $2.83-2.98$ & $5.71-8.21$ & $40-46$ & $0.36-0.40$ \\
\hline 1997/SK & GI5 & $7 \mathrm{DL}$ & barc76-cfa2257a & 2.82 & 10.92 & 41 & 0.38 \\
\hline 1998/SC & GI5-10 & 7DL & barc76-cfa2257a & $2.90-3.23$ & $3.51-8.00$ & $14-46$ & $0.33-0.41$ \\
\hline 1997/SC & PG5,14 & 7DL & barc76-cfa2257a & $2.87-2.96$ & $7.26-9.72$ & $44-47$ & $43.68-47.94$ \\
\hline 1997/SK & PG3 & 7DL & barc76-cfa2257a & 3.03 & 6.69 & 39 & 38.48 \\
\hline 1998/SC & PG5 & $7 \mathrm{DL}$ & barc76-cfa2257a & 2.85 & 7.48 & 45 & 44.78 \\
\hline 1998/SK & PG10 & 7DL & barc76-cfa2257a & 2.99 & 3.23 & 30 & 38.27 \\
\hline
\end{tabular}

SC: Swift Current; SK: Saskatoon; GH: greenhouse; CIM: composite interval mapping

${ }^{a}$ Based on Somers et al. (2004); Kumar et al. (2013), S: short arm; L: long arm

b Nearest SSR markers to the QTL peak is underlined

c Based on 1000 permutations (values given in range for respective trait measure with multiple durations)

${ }^{\mathrm{d}}$ Maximum likelihood LOD score for the QTL (values given in range for respective trait measure with multiple durations)

e Phenotypic variation explained by the QTL (values given in range for respective trait measure with multiple durations)

${ }^{\mathrm{f}}$ Positive sign in germination resistance (GR) and negative sign in germination index (GI) and in percent germination (PG) indicated that SC8021-V2 allele contributed resistance for respective trait measure-duration relative to the AC Karma allele (values given in range for respective trait measure with multiple durations)

g QTL designation (favourable parental allele)

7D2; therefore these QTL are considered novel. They had medium to large effects in enhancing seed dormancy for protection against pre-harvest sprouting. The remaining 20 QTL were detected either at the same marker or overlapping marker intervals reported previously.

Several QTL were anticipated based on previous research into the population by Knox et al. (1998) who indicated a conservative minimum of seven effective factors. The two parents, SC8021-V2 and AC Karma, are genetically diverse with a low coefficient of parentage (Knox et al. 2014) suggesting they possess a diversity of factors for dormancy. As expected from previous research (DePauw and McCaig 1991; McCaig and DePauw 1992; Knox et al. 2012), genotype SC8021-V2 was sprouting resistant but less so than the red-seeded cultivar RL4137, and AC Karma was more sprouting susceptible. The considerable variation for dormancy across the various durations of germination and transgressive segregation beyond SC8021-V2, suggested AC Karma possessed genetic factors contributing to dormancy. AC Karma contributed QTL for increased dormancy on chromosomes 2A, 3A, 3B, 3D, 4A, 4D, 6A and 7D. The continuous normal and skewed distributions of the population indicated that multiple minor alleles are involved in controlling seed dormancy. This complex genetic control of dormancy is consistent with earlier studies (Knox et al. 1998; Kulwal et al. 2004; Imtiaz et al. 2008; Mohan et al. 2009; Fofana et al. 2009). The 


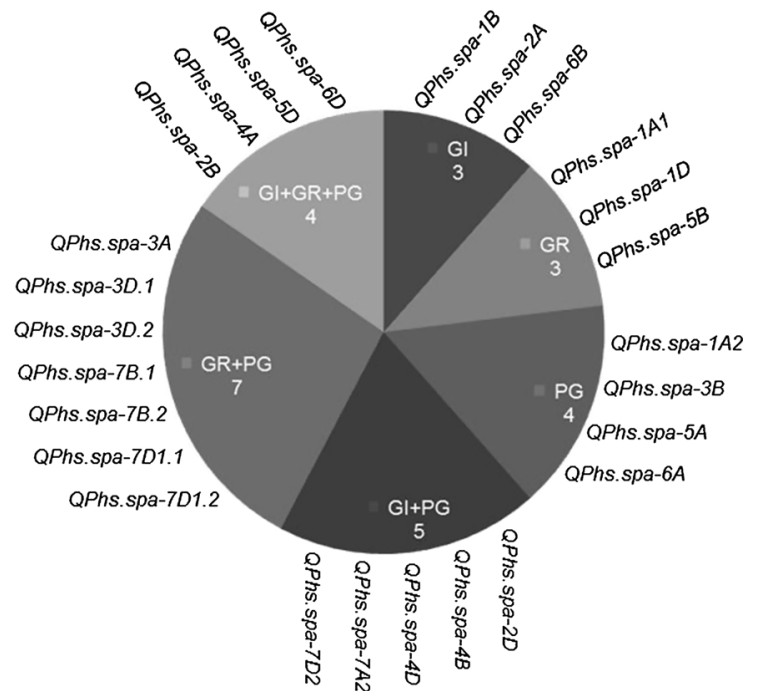

Fig. 3 Pie chart illustrating the number of pre-harvest sprouting resistance associated QTL detected in SC8021-V2/AC Karma doubled haploid mapping population for combinations of measurement methods of dormancy where GI: germination index, GR: germination resistance, PG: percent germination

different durations of germination maximized differential under some conditions, revealing a bimodal distribution that indicated, in addition to minor genes, the presence of a major gene.

Testing the population under different environments provided the opportunity to sample the effect of differentially expressed genes, while analysis of germination measures and durations provided opportunity to reveal the QTL. The complexity of dormancy was demonstrated with the revelation of many genetic loci differentially responding to varied environmental cues. First, the variation in dormancy of genotypes was revealed among environments for each of the three trait measures. For example, Swift Current and Saskatoon field trials showed a clear difference in level of dormancy. Second, the variation was revealed by differences in correlations among the germination measure-duration combinations over environments. Even when correlations were high among measures, variation existed for gene expression. For example, PG21d revealed more significant QTL than PG14d, indicating greater differences in information content between these durations than the high correlation suggested. Based on the frequency distributions, the greatest differential between less dormant and more dormant genotypes was with GI5d, GR21d and PG5d for field environments and GI10d, GR21d and PG7d for the GH environment. Even though these germination measures-durations tended to reveal the most QTL, many exceptions occurred. As indicated by Knox et al. (2012), a variety of germination measures and counting intervals should be used to maximize identification of QTL. The continuous distributions, transgressive segregation, low correlations between certain combinations of germination measure-durations, and variation of response among the different environments demonstrate the complexity and support the resolution of 26 QTL involving all 21 chromosomes.

Four pre-harvest sprouting QTL expressed consistently for GI, GR and PG measures at different germination durations: QPhs.spa-2B, QPhs.spa-5D and $Q P h s . s p a-6 D$ across multiple environments and QPhs.spa-4A in a single environment. QPhs.spa-4A was considered real because it explained up to $33 \%$ of the phenotypic variation for that environment. The environment insensitive QPhs.spa-5D is near the region Fofana et al. (2009) identified a QTL, QSi.crc-5D, on chromosome 5D associated with lower sprouting index. QSi.crc-5D was independent of seed coat colour but sensitive to environments. QTL on chromosome 5D were also reported by Anderson et al. (1993), Kulwal et al. (2004) and Jaiswal et al. (2012).

QTL QPhs.spa-2B identified in interval gwm55a$w m c 546 c$ on chromosome $2 \mathrm{~B}$ is merely $2.1 \mathrm{cM}$ from the TaSdr-Bl gene (Zhang et al. 2014) between wmc477-barc55 which regulates seed dormancy. Given that mapping of markers and QTL analysis uses best fit algorithms and noise in the data affects precision, it is possible that $Q P h s . s p a-2 B$ is identifying the gene $T a S d r-B 1$. Knox et al. (2012) also discovered a SSR marker (wmc592) for pre-harvest sprouting resistance on chromosome $2 \mathrm{~B}$ of durum wheat near QPhs.spa-2B QTL. The QPhs.spa-2B is in close proximity to $g w m 55 a$, where Hanocq et al. (2004) reported a photoperiod sensitive QTL for the Ppd-B1 gene. Munkvold et al. (2009) found a pre-harvest sprouting resistance QTL (QHd.cnl-2B.1) overlapped with dormancy and heading date at gwm429 on chromosome 2B. It is possible that QPhs.spa-2B corresponds to Ppd-B1. Pre-harvest sprouting resistance QTL on chromosome 2B were also reported by Kumar et al. (2009) and Miao et al. (2013).

The QPhs.spa-2D QTL is $16 \mathrm{cM}$ from Qphs.sau$2 D$ discovered by Ren et al. (2008) in a synthetic hexaploid $\times$ bread wheat cross. Several other studies reported pre-harvest sprouting QTL on chromosome 


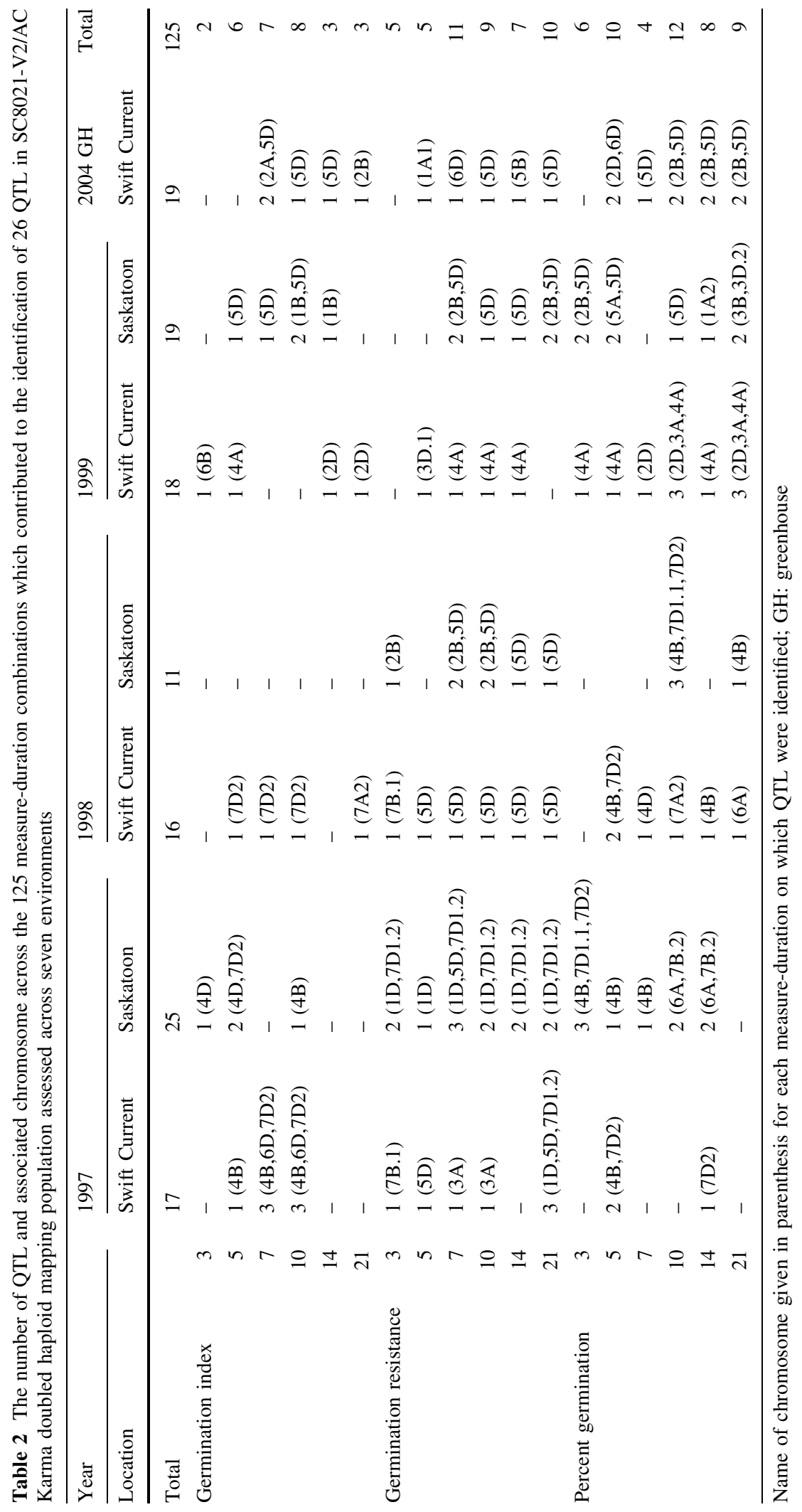


2D (Anderson et al. 1993; Mares et al. 2002; Mrva and Mares 2002; Hanocq et al. 2004; Tan et al. 2006; Munkvold et al. 2009). QPhs.spa-2D may be related to previously reported QTL. The QPhs.spa-6D QTL, detected in field and GH environments, mapped in the interval gwm325-cfd80 which is near the location of the germination inhibitor phytohormone $\mathrm{ABA}$ responsiveness gene $\mathrm{TaABA} 8^{\prime} \mathrm{OHI}$ (ABA $8^{\prime}$-hydroxylase activity) on chromosome $6 \mathrm{D}$. The gene plays a key role in seed dormancy regulation (Kobayashi et al. 2010; Chono et al. 2013; Iehisa et al. 2014).

Chromosomes of homoeologous group 4 are considered to have an effective role in pre-harvest sprouting resistance in wheat through dormancy control [Kulwal et al. 2010 (review); Lohwasser et al. 2013]. Noda et al. (2002) investigated another ABA responsive gene located on the long arm of chromosome 4A. QPhs.spa-4A, located in interval barc170-gwm397-wmc617a on $4 \mathrm{~A}$, is in a region associated with dormancy and preharvest sprouting resistance in numerous other QTL studies of hexaploid wheat (Flintham et al. 2002; Torada et al. 2005; Mares et al. 2005; Tan et al. 2006; Ogbonnaya et al. 2008; Imtiaz et al. 2008; Munkvold et al. 2009; Rasul et al. 2009; Kulwal et al. 2010; Singh et al. 2010, 2012; Lohwasser et al. 2013). The locus was also identified in tetraploid (Knox et al. 2012) and diploid (Nakamura et al. 2007) wheat populations, and in an association mapping study (Kulwal et al. 2012). It is possible that $Q P h s . s p a-4 A$ harbors the gene related to ABA responsiveness. Because a common SSR marker wmc617 amplifies DNA in all three homoeologous chromosomes (4A, 4B and 4D), it is reasonable to expect gene homoeologues for pre-harvest sprouting resistance among the group four chromosomes (Fig. 2). It is noteworthy that this region of chromosome $4 \mathrm{~A}$ and its probable homoeologous location on 4B (QPhs.spa$4 B ; w m c 617 b-w m c 48)$ and on 4D (QPhs.spa-4D; $w m c 617 c-w m c 89 b$ ) detected three major QTL for preharvest sprouting resistance in multiple environments. Our study appears to be the first report of QTL for preharvest sprouting resistance in the same homoeologous region of all three group four chromosomes. Given that QPhs.spa- $4 B$ had the largest effect, explaining on average $51 \%$ of the phenotypic variation, SC8021$\mathrm{V} 2$, the source of this resistance, is a good candidate for further ABA responsiveness gene analysis. Studies also show that the dwarfing genes (i.e. Rht-1, Rht-2, Rht-3) located on the group four chromosomes have pleiotropic effects on many plant characters including pre- harvest sprouting resistance (King et al. 1983; McIntosh 1988; Wu et al. 2011). The Rht-Blc variant exhibited insensitivity to $\mathrm{GA}_{3}$ which caused reduction in alphaamylase activity in seeds, increased ABA responsiveness and increased Hagberg falling number, resulting in improved resistance to sprouting damage (Flintham et al. 1997; Gooding et al. 2012). However, the location of Rht-B1c allele at wmcl25 on chromosome 4B (Navarro et al. 2014) is distant from the QPhs.spa-4B QTL.

The QPhs.spa-7A2 QTL strongly identified in the field environment and mapped to the short arm of chromosome 7A at interval wmc17-barc154 which is in a similar region as $Q P h s d . s p a-7 A$ reported by Knox et al. (2012) and $Q P h s . s p a-7 A$ reported by Singh et al. (2014) in durum wheat, and QPhs.ccsu-7A.1 reported by Mohan et al. (2009) in hexaploid wheat. This consistency suggests the 7A QTL is important for imparting pre-harvest sprouting resistance in different genetic backgrounds. The LOD peak of the chromosome 7B QPhs.spa-7B.1 QTL in interval gwm146$g w m 344 b$ was very close to the marker wmc526 reported by Jaiswal et al. (2012). Two QTL, QPhs.spa-7B.1 (1.9 cM) and QPhs.spa-7B.2 $(52.8 \mathrm{cM})$ are the first and second occurrences of QTL on chromosome 7B. Based on SSR markers in a consensus map of 7B from the GrainGenes database (http://wheat.pw. usda.gov/GG2/index.shtml), QPhs.spa-7B.2 at wm$c 405 b$ is near to the QTL QPhs.spa-7B reported by Singh et al. (2014) and QPhsd.spa-7B.1 reported by Knox et al. (2012) in durum wheat. Kobayashi et al. (2010) reported a QTL for ABA responsiveness on 7B which is $9 \mathrm{cM}$ away from QPhs.spa-7B.2. We considered the two QTL LOD peaks on chromosome segment 7D1 that spaced more than $50 \mathrm{cM}$ as two different QTL [QPhs.spa-7D1.1 $(21.6 \mathrm{cM})$ and QPhs.spa-7D1.2 (72.1 cM)]. The QPhs.cnl-7D2 QTL reported by Munkvold et al. (2009) on 7D is in the same region as QPhs.spa-7D1.1. The second QTL on chromosome 7D, QPhs.spa-7D1.2, in interval $w m c 463-w m c 698$ for the GR measure at day 3, 7, 10, 14 and 21 was novel. A major QTL QPhs.spa-7D2 on chromosome 7D2 (another linkage group of 7D) at interval barc76-cfa2257a was also novel. Using bulk segregant analysis in a DH population, Flintham (2000) also reported a gene, Phs, on chromosome 7D. These reports along with our findings indicate that factors on chromosome 7D have the capacity to control sprouting. 
Dormancy and thus pre-harvest sprouting resistance are associated with red pericarp (Groos et al. 2002). However, DePauw and McCaig (1983) and DePauw et al. (1992) recovered sprouting resistant white-seeded progeny from crosses of dormant redseeded by white-seeded sprouting susceptible parents which demonstrated that at least two mechanisms controlled pre-harvest sprouting resistance. The $R$ genes responsible for controlling red seed coat are present on the homoeologous group three chromosomes. The three QTL QPhs.spa-3A, QPhs.spa-3B and $Q P h s . s p a-3 D .2$ detected for GR and PG measures were co-localized with the three major QTL namely, QCL.crc-3A, QCL.crc-3B and QCL.crC-3D associated with red seed coat color identified by Fofana et al. (2009). These findings demonstrate substantial complexity with the same QTL being responsible for preharvest sprouting resistance in white and red-seeded wheat. No QTL were detected on group three chromosomes with GI, and those detected with GR and PG were weak and appeared in few environments. Perhaps different alleles of the seed coat color genes occur in white seed coat genotypes that still weakly affect dormancy but do not impart red color. Alternatively, the dormancy genes are only linked to the seed coat colour genes. The $3 \mathrm{~A}$ chromosome was previously associated with a pre-harvest sprouting resistance QTL (Rasul et al. 2009), Qphs.pseru-3AS, reported by Liu et al. (2008) and Liu and Bai (2010), although maps could not be cross-referenced. Liu et al. (2013) cloned a gene from white-seeded wheat which they designated TaPHS1. Another gene on chromosome 3A reported to be involved in controlling seed dormancy and germination is TaMFT-A1, a homoeologue of MOTHER OF FT (Nakamura et al. 2011; Lei et al. 2013). The structure of the TaMFT and TaPHS1 genes are the same except for some SNPs within the promoter and exon-intron sequences, and their relevance with the QTL we identified needs further work.

The QTL QPhs.spa-5A, with moderate effect in interval gwm304-cfa2190, is consistent with the interval of chromosome 5A detected for a pre-harvest sprouting QTL by Groos et al. (2002) and Glein et al. (2006). A QTL for ABA responsiveness (Iehisa et al. 2014) maps $7 \mathrm{cM}$ away from $Q P h s . s p a-5 A$ and was associated with dehydration tolerance and seed dormancy in a $F_{2}$ population of the cultivar Chinese Spring crossed with Chinese Spring (Hope5A).
Chinese Spring (Hope5A) is a chromosome substitution line of Chinese Spring with chromosome 5A of Hope. The putative QTL QPhs.spa-5B detected only for GR14d from the GH environment appears in the vicinity (11-13 cM) of the QTL reported in hexaploid wheat by Fofana et al. (2008) and in durum wheat by Singh et al. (2014).

The QPhs.spa-6A QTL mapped on chromosome 6A was revealed by PG from field environments and appears to map at least $30 \mathrm{cM}$ from the QPhs.ccsu$6 A .1$ reported by Kumar et al. (2009) based on the markers position on the consensus map of wheat by Maccaferri et al. (2014). Thus, QPhs.spa-6A may be a novel QTL. However, another pre-harvest sprouting QTL on 6A was reported by Zanetii (2000) using restriction fragment length polymorphism (RFLP) probes but it is difficult to relate this locus to QPhs.spa-6A. The minor QPhs.spa-6B QTL in interval gdm113-gwm508 is in the same region as a QTL reported by Glein et al. (2006) and Knox et al. (2012) in durum wheat populations.

The QTL, QPhs.spa-1D, that expressed strongly for the GR3-21d in interval wmc222-wmc216 is in the same region which Kumar et al. (2009) reported for grain colour (wmc222). As with the red seed coat genes of the group three chromosomes, one may hypothesize the overlap as being related in function. Lohwasser et al. (2013) also reported dormancy QTL QD20.ipk-1D on chromosome 1D just $2.2 \mathrm{cM}$ from $Q P h s . s p a-1 D$. The minor effect QPhs.spa-1Al QTL at cfa2135 coincides with a QTL reported by Knox et al. (2012) and Jaiswal et al. (2012), and is near to QTL reported in many other studies (Glein et al. 2006; Munkvold et al. 2009; Mohan et al. 2009; Singh et al. 2010; Rehman et al. 2012; Singh et al. 2014). Singh et al. (2010) and Zanetti et al. (2000) detected a QTL on chromosome $1 \mathrm{~A}$ that was possibly involved with alpha-amylase activity, an important predictor of preharvest sprouting. QPhs.spa-1B in interval wmc44gwm 328 that explained $18 \%$ of the phenotypic variation for GI10d and GI14d is in a different position from QTL reported by Munkvold et al. (2009), Jaiswal et al. (2012) and Singh et al. (2014). Therefore QPhs.spa-1B may be independent of their 1B QTL.

QTL, QPhs.spa-2A, for GI7d from the GH environment was in interval gwm294-cfa2058 on chromosome 2A, a different position from the previous reports (Mohan et al. 2009; Kumar et al. 2009; Kobayashi 
et al. 2010; Jaiswal et al. 2012; Knox et al. 2012). The marker coverage was low on chromosome $2 \mathrm{~A}$ which may affect the QTL position and this conclusion.

Our study differed from other studies (Biddulph et al. 2008; Singh et al. 2008; Knox et al. 2012) with not only the application of multiple measures of seed dormancy but also with multiple time intervals during germination up to 21 days across multiple environments. This is the first report in which QTL associated with the seed dormancy component of pre-harvest sprouting resistance were detected and mapped on all the chromosomes. This intense set of measurements was intended to capture maximum expression of genes in chromosomal regions (QTL) influencing pre-harvest sprouting resistance. Knox et al. (1998) first used the phenotypic data collected on the SC8021-V2/AC Karma population to estimate that more than seven effective factors segregated with traditional quantitative analysis. The addition of marker data for QTL analysis further elucidated the complexity of sprouting resistance and demonstrated that far more QTL were involved. The majority of the QTL align with previously reported QTL. This alignment not only validates the QTL, but that the intensive measuring protocol and analysis is important to revealing dormancy QTL segregating in a population. The QTL identified in this study, through comparisons in the literature of commonly mapped markers, were associated with important components of pre-harvest sprouting resistance such as seed coat colour, ABA responsiveness, and alpha-amylase activity. The QTL ranged from minor to major, some were previously reported, some were identified in different environments and genetic backgrounds, some appear to be validated based on common locations with previously reported QTL, and others appear to be novel. Six QTL we describe as novel in the sense that they were previously unidentified yet influence control of pre-harvest sprouting. Further validation is required for several of the QTL.

As demonstrated, the genetic control of dormancy and thus pre-harvest sprouting resistance is complex, and the genes at several loci across the whole genome are greatly influenced by the environment. Even though many more QTL were identified in the SC8021-V2/AC Karma population than previously reported in a single mapping population, several QTL reported by others were not detected here. The possible reasons for not detecting QTL relate to (i) lack of presence of alleles in the parental genotypes, (ii) effective alleles were common between the two parents so no segregation occurred, (iii) sampled environments were not conducive to expression, and (iv) unsaturated coverage of the genome due to lack of polymorphic markers and therefore low-resolution of the genetic map. Variation in pre-harvest sprouting resistance may also exist beyond main effect QTL, such as epistatic interactions. Such analysis remains to be done. Challenges remain, such as determining why apparent homoeologous QTL located on the group three chromosomes, which are associated with red grain colour, also appear to control pre-harvest sprouting in red- and white-seeded wheat. Similarly, the relationship of homoeologous QTL variants detected on $4 \mathrm{~A}, 4 \mathrm{~B}$ and 4D need to be confirmed using other populations or by sequencing of the regions of interest.

Understanding the major QTL for pre-harvest sprouting resistance detected on chromosomes $1 \mathrm{~A}$, 1D, 2B, 4A, 5D, 6D, 7D observed through measuring different durations of germination with GI, GR and PG may aid in marker-assisted breeding for improved preharvest sprouting resistance in wheat. The study also revealed that favourable alleles for improving sprouting resistance were present in both SC8021-V2 and AC Karma parents. The markers associated with the transgressive segregant genotypes for sprouting resistance from the SC8021-V2/AC Karma population can be used to further develop more resistant white-seeded wheat cultivars.

This study with hexaploid wheat confirmed the approach reported by Knox et al. (2012) with durum wheat to maximize identification of QTL contributing to dormancy. Our results support conclusions of other researchers that QTL for pre-harvest sprouting resistance are located on all the wheat chromosomes (Flintham et al. 2002). Pyramiding of these QTL will boost the level of resistance to pre-harvest sprouting in white-seeded wheat cultivars. In this era of genomics, the availability of chromosome-based sequences and high-throughput genotyping platforms for construction of high-resolution genetic maps will allow further fine mapping and better understanding of pre-harvest sprouting resistance QTL.

Acknowledgments We gratefully acknowledge the financial support of the Agriculture and Agri-Food Canada (AAFC), Western Grain Research Foundation (WGRF) and Genome Canada [Canadian Triticum Advancement through Genomics (CTAG)] to carry out this study. Technical assistance provided 
by Heather Campbell, Alison Banman, Cam Barlow, Theresa Colenutt, Brad Meyer and members of the wheat work group at Semiarid Prairie Agricultural Research Centre (SPARC) is sincerely appreciated.

Conflict of interest The authors declare that they have no conflict of interest.

Open Access This article is distributed under the terms of the Creative Commons Attribution 4.0 International License (http:// creativecommons.org/licenses/by/4.0/), which permits unrestricted use, distribution, and reproduction in any medium, provided you give appropriate credit to the original author(s) and the source, provide a link to the Creative Commons license, and indicate if changes were made.

\section{References}

Anderson JA, Sorrells ME, Tanksley SD (1993) RFLP analysis of genomic regions associated with resistance to pre-harvest sprouting in wheat. Crop Sci 33:453-459

Balyan HS, Gupta PK, Kumar S, Dhariwal R, Jaiswal V, Tyagi S, Agarwal P, Gahlaut V, Kumari S (2013) Genetic improvement of grain protein content and other health-related constituents of wheat grain. Plant Breed 132:446-457

Biddulph TB, Plummer JA, Setter TL, Mares DJ (2008) Seasonal conditions influence dormancy and pre-harvest sprouting tolerance of wheat (Triticum aestivum L.) in the field. Field Crops Res 107:116-128

Braun HJ, Atlin G, Payne T (2010) Multi-location testing as a tool to identify plant response to global climate change. In: Reynolds CRP (ed) Climate change and crop production. CABI Publishers, London

Chono M, Matsunaka H, Seki M, Fujita M, Kiribuchi-Otobe C, Oda S, Kojima H, Kobayashi D, Kawakami N (2013) Isolation of a wheat (Triticum aestivum L.) mutant in ABA 8-hydroxylase gene: effect of reduced ABA metabolism on germination inhibition under field condition. Breed Sci 63:104-115

Clarke FR, Clarke JM, DePauw RM, Fernandez MR, Fox S, Gilbert J, Humphreys DG, Knox RE, McCaig TN, Procunier D, Sissons M, Somers D (2005) Strategic approach to mitigating weather induced defects of wheat quality. Euphytica 143:285-290

DePauw RM, McCaig TN (1983) Recombining dormancy and white seed colour in a spring wheat cross. Can J Plant Sci 63:581-589

DePauw RM, McCaig TN (1991) Components of variation, heritabilities and correlations for indices of sprouting tolerance and seed dormancy in Triticum spp. Euphytica 52:221-229

DePauw RM, Townley-Smith TF, McCaig TN, Clarke JM, McLeod JM, Knox RE (1989) HY355 white spring wheat. Can J Plant Sci 69:1245-1250

DePauw RM, McCaig TN, Clarke JM, McLeod JG, Knox RE, Fernandez MR (1992) Registration of sprouting-tolerant white-kernelled wheat germplasms SC8019-R1 and SC8021-V2. Crop Sci 32:838
DePauw RM, McCaig TN, Knox RE, Clarke JM, Fernandez MR, McLeod JG (1998) AC vista hard white spring wheat. Can J Plant Sci 78:617-620

DePauw RM, Clarke FR, Fofana B, Knox R, Humphreys G, Cloutier S (2009) RL4137 contributes pre-harvest sprouting resistance to Canadian wheats. Euphytica 168:347-361

DePauw RM, Knox RE, Singh AK, Fox S, Humphreys DG, Hucl $P$ (2012) Developing standardized methods for breeding pre-harvest sprouting resistant wheat, challenges and successes in Canadian wheat. Euphytica 188:7-14

Fang J, Chu C (2008) Abscisic acid and the pre-harvest sprouting in cereals. Plant Signal Behav 3:1046-1048

Flintham JE (2000) Different genetic components control coat imposed and embryo-imposed dormancy in wheat. Seed Sci Res 10:43-50

Flintham JE, Angus WJ, Gale MD (1997) Heterosis, overdominance for grain yield, and alpha-amylase activity in F1 hybrids between near-isogenic Rht dwarf and tall wheats. J Agric Sci 129:371-378

Flintham JE, Adlam RE, Bassoi M, Holdsworth M, Gale MD (2002) Mapping genes for resistance to sprouting damage in wheat. Euphytica 126:39-45

Fofana B, Humphreys G, Rasul G, Cloutier S, Somers D (2008) Assessment of molecular diversity at QTLs for pre-harvest sprouting resistance in wheat using microsatellite markers. Genome 51:375-386

Fofana B, Humphreys DG, Rasul G, Cloutier S, Brule-Babel A, Woods S, Lukow OM, Somers DJ (2009) Mapping quantitative trait loci controlling pre-harvest sprouting resistance in a red $\times$ white seeded spring wheat cross. Euphytica 165:509-521

Gao X, Hu CH, Li HZ, Yao YJ, Meng M, Dong J, Zhao WC, Chen QJ, Li XY (2013) Factors affecting pre-harvest sprouting resistance in wheat (Triticum aestivum L.): a review. J Anim Plant Sci 23:556-565

Gillies SA, Futardo A, Henry RJ (2012) Gene expression in the developing aleurone and starchy endosperm of wheat. Plant Biotechnol 10:668-679

Glein JR, Elias EM, Kianian SF (2006) Evaluation of two durum wheat (Triticum turgidum L. var. durum) crosses for pre-harvest sprouting resistance. Field Crops Res 97:188-196

Gooding MJ, Uppal RK, Addisu M, Harris KD, Uauy C (2012) Reduced height alleles $(R h t)$ and Hagberg falling number of wheat. J Cereal Sci 55:305-311

Gordon AG (1971) The germination resistance test: a new test for measuring germination quality of cereals. Can J Plant Sci 51:181-183

Graeber K, Nakabayashi K, Miatton E, Leubner-Metzger G, Soppe WJJ (2012) Molecular mechanisms of seed dormancy. Plant, Cell Environ 35:1769-1786

Groos C, Gay G, Perretant M-R, Gervais L, Bernard M, Dedryver F, Charmet G (2002) Study of the relationship between pre-harvest sprouting and grain colour by quantitative trait loci analysis in white $\times$ red grain bread wheat cross. Theor Appl Genet 104:39-47

Hanocq E, Niarquin M, Heumez E, Rousset M, Le Gouis J (2004) Detection and mapping of QTL for earliness components in a bread wheat recombinant inbred lines population. Theor Appl Genet 110:106-115 
Hedman H, Kallman T, Lagercrantz U (2009) Early evolution of the MFT-like gene family in plants. Plant Mol Biol 70:359-369

Himi E, Noda K (2005) Red grain colour gene (R) of wheat is a Myb-type transcription factor. Euphytica 143: 239-242

Himi E, Mares DJ, Yanagisawa A, Noda K (2002) Effect of grain colour gene $(\mathrm{R})$ on grain dormancy and sensitivity of the embryo to abscisic acid (ABA) in wheat. J Exp Bot 53:1569-1574

Huang XQ, Brule-Babel A (2012) Sequence diversity, haplotype analysis, association mapping and functional marker development in the waxy and starch synthase IIa genes for grain-yield-related traits in hexaploid wheat (Triticum aestivum L.). Mol Breed 30:627-645

Iehisa JCM, Matsuura T, Mori IC, Yokota H, Kobayashi F, Takumi S (2014) Identification of quantitative trait loci for abscisic acid responsiveness in the D-genome of hexaploid wheat. J Plant Physiol 171:830-841

Imtiaz M, Ogbonnaya FC, Oman J, Ginkel MV (2008) Characterization of quantitative trait loci controlling genetic variation for pre-harvest sprouting in synthetic backcrossderived wheat lines. Genetics 178:1725-1736

Jaiswal V, Mir RR, Mohan A, Balyan HS, Gupta PK (2012) Association mapping for pre-harvest sprouting tolerance in common wheat (Triticum aestivum L.). Euphytica 188:89-102

King RW, Gale MD, Quarrie SA (1983) Effect of Norin 10 and Tom Thumb dwarfing genes on morphology, physiology and abscisic acid production in wheat. Ann Bot 51:201-208

Knox RE, DePauw RM, McCaig TN, Clarke JM, Mcleod JG, Femandez MR (1995) AC Karma white spring wheat. Can J Plant Sci 75:899-901

Knox RE, Fox SL, Clarke FR, Clarke JM, DePauw RM, Howes NK, Armstrong KC, Procunier JD (1998) Genetic analysis of dormancy in Triticum aestivum and Triticum turgidum. In: Slinkard AE (ed) Proceedings of the 9th international wheat genetics symposium, Vol. 4, Print Crafters Inc., Winnipeg, pp 45-47

Knox RE, Clarke JM, DePauw RM (2000) Dicamba and growth conditions effects on doubled haploid production in durum wheat crossed with maize. Plant Breed 119:289-298

Knox RE, Clarke FR, Clarke JM, Fox SL (2005) Genetic analysis of pre-harvest sprouting in a durum wheat cross. Euphytica 143:261-264

Knox RE, Clarke FR, Clarke JM, Fox SL, DePauw RM, Singh AK (2012) Enhancing the identification of genetic loci and transgressive segregant for pre-harvesting sprouting resistance in a durum wheat population. Euphytica 186: 193-206

Knox RE, Campbell HL, Clarke FR, Menzies JG, Popovic Z, Procunier JD, Depauw RM, Cuthbert RD (2014) Quantitative trait loci for resistance in wheat (Triticum aestivum) to Ustilago tritici. Can J Plant Pathol 36:187-201

Kobayashi F, Takumi S, Handa H (2010) Identification of quantitative trait loci for $\mathrm{ABA}$ responsiveness at the seedling stage associated with ABA-regulated gene expression in common wheat. Theor Appl Genet 121:629-641
Kosambi DD (1944) The estimation of map distances from recombination values. Ann Eugen 12:172-175

Kulwal PL, Singh R, Balyan HS, Gupta PK (2004) Genetic basis of pre-harvest sprouting tolerance using single-locus and two-locus QTL analyses in bread wheat. Funct Integr Genomics 4:94-101

Kulwal PL, Mir RR, Kumar S, Gupta PK (2010) QTL analysis and molecular breeding for seed dormancy and pre-harvest sprouting tolerance in bread wheat. J Plant Biol 37:59-74

Kulwal PL, Ishikawa G, Benscher D, Feng Z, Yu L-X, Jadhav A, Mehetre S, Sorrells ME (2012) Association mapping of pre-harvest sprouting resistance in white winter wheat. Theor Appl Genet 125:793-805

Kumar A, Kumar J, Singh R, Garg T, Chuneja P, Balyan HS, Gupta PK (2009) QTL analysis for grain colour and pre-harvest sprouting in bread wheat. Plant Sci 177:114-122

Kumar S, Goyal A, Mohan A, Balyan HS, Gupta PK (2013) An integrated physical map of simple sequence repeats in bread wheat. Aust J crop Sci 7(4):460-468

Lei L, Zhu X, Wang S, Zhu M, Carver BF, Yan L (2013) TaMFT-Al is associated with seed germination sensitive to temperature in winter wheat. PLoS ONE 8(9):e73330

Littell RC, Milliken GA, Stroup WW, Wolfinger RD (1996) SAS system for mixed models. SAS Institute Inc, Cary

Liu SB, Bai GH (2010) Dissection and fine mapping of a major QTL for pre-harvest sprouting resistance in white wheat Rio Blanco. Theor Appl Genet 121:1395-1404

Liu SB, Cai SB, Graybosch R, Chen CX, Bai GH (2008) Quantitative trait loci for resistance to pre-harvest sprouting in US hard white winter wheat Rio Blanco. Theor Appl Genet 117:691-699

Liu SB, Sehgal SK, Li J, Lin M, Trick HN, Yu J, Gill BS, Bai GH (2013) Cloning and characterization of a critical regulator for pre-harvest sprouting in wheat. Genetics 195:263-273

Lohwasser U, Rehman Arif MA, Borner A (2013) Discovery of loci determining pre-harvest sprouting and dormancy in wheat and barley applying segregation and association mapping. Biol Plant 57:663-674

Maccaferri M, Cane MA, Sanguineti MC, Salvi S, Colalongo MC, Massi A, Clarke F, Knox R, Pozniak CJ, Clarke JM, Fahima T, Dubcovsky J, Xu S, Ammar K, Karsai I, Vida G, Tuberosa R (2014) A consensus framework map of durum wheat (Triticum durum Desf.) suitable for linkage disequilibrium analysis and genome-wide association mapping. BMC Genomics 15:873

Mares DJ (1987) Pre-harvest sprouting tolerance in white grained wheat. In: Mares DJ (ed) Fourth International Symposium on Pre-harvest Sprouting in Cereals. Westview Press, Boulder, pp 64-74

Mares DJ, Mrva K, Tam M, Sharp P (2002) Dormancy in whitegrained wheat: progress towards identification of genes and molecular markers. Euphytica 126:47-53

Mares DJ, Mrva K, Cheong J, Williams K, Watson B, Storlie E, Sutherland M, Zou Y (2005) A QTL located on chromosome $4 \mathrm{~A}$ associated with dormancy in white and red grained wheats of diverse origin. Theor Appl Genet 111:1357-1364 
McCaig TN, DePauw RM (1992) Breeding for pre-harvest sprouting tolerance in white-seed-coat spring wheat. Crop Sci 32:19-23

McIntosh RA (1988) Catalogue of gene symbols for wheat. Proceedings 7th international wheat genetics symposium, Cambridge, Vol. 2, pp 1225-1323

McIntosh RA, Hart GE, Devos KM, Gale MD, Rogers WJ (1998) Catalogue of gene symbols for wheat. Proceedings 9th international wheat genetics symposium, Vol. 5, University of Saskatchewan, Extension Press, Canada

Miao XL, Zhang YJ, Xia XC, He ZH, Zhang Y, Yan J, Chen XM (2013) Mapping quantitative trait loci for pre-harvest sprouting resistance in white-grained winter wheat line CA0431. Crop Pasture Sci 64:573-579

Mohan A, Kulwal P, Singh R, Kumar V, Mir RR, Kumar J, Prasad M, Balyan HS, Gupta PK (2009) Genome-wide QTL analysis for pre-harvest sprouting tolerance in bread wheat. Euphytica 168:319-329

Mori M, Uchino N, Chono M, Kato K, Miura H (2005) Mapping QTLs for grain dormancy on wheat chromosome 3A and the group 4 chromosomes, and their combined effect. Theor Appl Genet 110:1315-1323

Mrva K, Mares DJ (2002) Screening methods and identification of QTL associated with late maturity alpha-amylase in wheat. Euphytica 126:55-59

Munkvold JD, Tanaka J, Benscher D, Sorrells ME (2009) Mapping quantitative trait loci for pre-harvest sprouting resistance in white wheat. Theor Appl Genet 119:1223-1235

Nakamura S, Komatsuda T, Miura H (2007) Mapping diploid wheat homologues of Arabidopsis seed ABA signaling genes and QTLs for seed dormancy. Theor Appl Genet 114:1129-1139

Nakamura S, Abe F, Kawahigashi H, Nakazono K, Tagiri A, Matsumoto T, Utsugi S, Ogawa T, Handa H, Ishida H, Mori M, Kawaura K, Ogihara Y, Miura H (2011) A wheat homolog of MOTHER OF FT AND TFL1 acts in the regulation of germination. Plant Cell 23:3215-3229

Navarro C, Yang Y, Mohan A, Grant N, Gill KS (2014) Microsatellites based genetic linkage map of the Rht3 locus in bread wheat. Mol Plant Breed 5:43-46

Nilsson-Ehle H (1914) Zur Kentnis der mit der Keimungsphysiologie des Weizens in Zusammenhang stehenden innerern Faktoren. $\mathrm{Z}$ pflanzenzuchtung 2:153-157

Noda K, Matsuura T, Maekawa M, Taketa S (2002) Chromosomes responsible for sensitivity of embryo to abscisic acid and dormancy in wheat. Euphytica 123:203-209

Ogbonnaya FC, Imtiaz M, Ye G, Hearnden PR, Hernandez E, Eastwood RF, Ginkel MV, Shorter SC, Winchester JM (2008) Genetic and QTL analyses of seed dormancy and pre-harvest sprouting resistance in the wheat germplasm CN10955. Theor Appl Genet 116:891-902

Rasul G, Humphreys DG, Brule-Babel A, McCartney CA, Knox RE, DePauw RM, Somers DJ (2009) Mapping QTLs for pre-harvest sprouting traits in the spring wheat cross 'RL4452/AC Domain'. Euphytica 168:363-378

Rawlings JO (1988) Applied regression analysis: a research tool. Wadsworth and Brooks Inc., Belmont, pp 250
Reddy LV, Metzger RJ, Ching TM (1985) Effect of temperature on seed dormancy of wheat. Crop Sci 25:455-458

Rehman Arif MA, Neumann K, Nagel M, Kobiljski B, Lohwasser U, Borner A (2012) An association mapping analysis of dormancy and pre-harvest sprouting in wheat. Euphytica 188:409-417

Ren XB, Lan XJ, Liu DC, Wang JL, Zheng YL (2008) Mapping QTLs for pre-harvest sprouting tolerance on chromosome $2 \mathrm{D}$ in a synthetic hexaploid wheat $\times$ common wheat cross. J Appl Genet 49:333-341

Roy JK, Prasad M, Varshney RK, Balyan HS, Blake TK, Dhaliwal HS, Singh H, Edwards KJ, Gupta PK (1999) Identification of a microsatellite on chromosomes $6 \mathrm{~B}$ and a STS on 7D of bread wheat showing an association with preharvest sprouting tolerance. Theor Appl Genet 99:336-340

Singh R, Matus-Cadiz MA, Baga M, Hucl P, Chibbar RN (2008) Comparisons of different methods for phenotyping preharvest sprouting in white-grained wheat. Cereal Chem 85:238-242

Singh R, Matus-Cadiz MA, Baga M, Hucl P, Chibbar RN (2010) Identification of genomic regions associated with seed dormancy in white-grained wheat. Euphytica 174:391-408

Singh R, Hucl P, Baga M, Chibbar RN (2012) Validation of molecular markers for pre-harvest sprouting resistance in bread wheat. Cereal Res Commun 40:194-203

Singh AK, Knox RE, Clarke JM, Clarke FR, Singh A, DePauw RM, Cuthbert RD (2014) Genetics of pre-harvest sprouting resistance in a cross of Canadian adapted durum wheat genotypes. Mol Breed 33:919-929

Somers DJ, Issac P, Edwards K (2004) A high-density microsatellite consensus map for bread wheat (Triticum aestivum L.). Theor Appl Genet 109:1105-1114

Tan M-K, Sharp PJ, Lu M-Q, Howes N (2006) Genetics of grain dormancy in a white wheat. Aust J Agric Res 57:1157-1165

Torada A, Ikeguchi S, Koike M (2005) Mapping and validation of PCR-based markers associated with a major QTL for seed dormancy in wheat. Euphytica 143:251-255

Van Ooijen JW (2011) Multipoint maximum likelihood mapping in a full-sib family of an outbreeding species. Genet Res 93(5):343-349

Walker-Simmons M (1988) Enhancement of ABA responsiveness in wheat embryos by high temperature. Plant, Cell Environ 11:769-775

Wang S, Basten CJ, Zeng Z-B (2012) Windows QTL Cartographer 2.5. Department of Statistics, North Carolina State University, Raleigh, NC

Wu J, Kong X, Wan J, Liu X, Zhang X, Guo X, Zhou R, Zhao G, Jing R, Fu X, Jia J (2011) Dominant and pleiotropic effects of a $G A I$ gene in wheat results from lack of interaction between DELLA and GID1. Plant Physiol 157:2120-2130

Zanetti S, Winzeler M, Keller M, Keller B, Messmer M (2000) Genetic analysis of pre-harvest sprouting resistance in a wheat $\times$ spelt cross. Crop Sci 40:1406-1417

Zhang Y, Miao X, Xia X, He Z (2014) Cloning of seed dormancy genes ( $T a S d r)$ associated with tolerance to preharvest sprouting in common wheat and development of a functional marker. Theor Appl Genet 127:855-866 